$14912 / 6-96-$ 207261

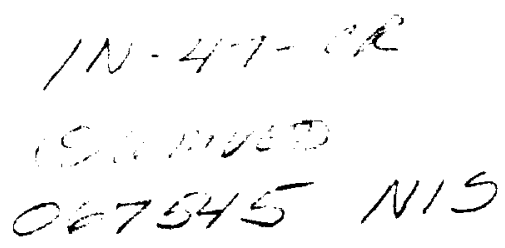

\title{
Cloud Radiation Forcings and Feedbacks: General Circulation Model Tests and Observational Validation
}

\author{
Wan-Ho Lee, Sam F. Iacobellis, and Richard C. J. Somerville \\ Climate Research Division, Scripps Institution of Oceanography, University of California, San Diego, La Jolla. California
}

(Manuscript received 25 March 1996, in final form 8 November 1996)

\section{ABSTRACT}

\begin{abstract}
Using an atmospheric general circulation model (the National Center for Atmospheric Research Community Climate Madel: CCM2), the effects on climate sensitivity of several different cloud radiation parameterizations have been investigated. In addition to the original cloud radiation scheme of CCM2, four parameterizations incorporating prognostic cloud water were tested: one version with prescribed cloud radiative properties and three other versions with interactive cloud radiative properties. The authors' numerical experiments employ perpetual July integrations driven by globally constant sea surface temperature forcings of two degrees, both positive and negative.

A diagnostic radiation calculation has been applied to investigate the partial contributions of high. middle, and low cloud to the total cloud radiative forcing, as well as the contributions of water vapor, temperature, and cloud to the net climate feedback. The high cloud net radiative forcing is positive, and the middle and low cloud cloud to the net climate feedicise the total net cloud forcing is negative in all of the model versions. The effect of interactive cloud radiative properties on global climate sensitivity is significant. The net cloud radiative feedbacks consist of quite different shortwave and longwave components between the schemes with interactive cloud radiative properties and the schemes with specified properties. The increase in cloud water content in the warmer climate leads to optically thicker middle- and low-level clouds and in turn to negative shortwave feedbacks warmer climate leads to optically hicker mile the decrease in cloud amount simply produces a positive shortwave feedback for the schemes with a specified cloud water path. For the longwave feedbacks, the decrease in high feedback for the scheme cloudiness for the schemes without interactive radiative properties leads to a negative feedback, while for the other cases, the longwave feedback is positive.

These cloud radiation parameterizations are empirically validated by using a single-column diagnostic model. together with measurements from the Atmospheric Radiation Measurement program and from the Tropical Ocean Global Atmosphere Combined Ocean-Atmosphere Response Experiment. The inclusion of prognostic cloud water produces a notable improvement in the realism of the parameterizations, as judged by these observations. Furthermore, the observational evidence suggests that deriving cloud radiative properties from cloud water content and microphysical characteristics is a promising route to further improvement.
\end{abstract}

\section{Introduction}

The net effect of clouds on the radiation balance of the earth, referred to as the cloud radiative forcing, is negative (Ramanathan et al. 1989) and has an average magnitude of about $10-20 \mathrm{~W} \mathrm{~m}^{-2}$. It consists of a shortwave cooling (the albedo effect) of about $40-50 \mathrm{~W} \mathrm{~m}^{-2}$ and a longwave warming (the greenhouse effect) of about $30 \mathrm{~W} \mathrm{~m}^{-2}$. The size of the observed average net cloud forcing is several times the expected value of the direct radiative forcing from a doubling of $\mathrm{CO}_{2}$ (about

\footnotetext{
* Current affiliation: Systems Engineering Research Institute, Yoosung-Gu, Taejun. Choongnam, Korea.
}

Corresponding author address: Prof. Richard C. J. Somerville Scripps Institution of Oceanography. University of California, San Diego, 9500 Gilman Drive, Dept. 0224, La Jolla, CA 92093-0224.
$4 \mathrm{~W} \mathrm{~m}^{-2}$ ), suggesting that cloud effects can play a significant role in climate change.

Parameterization of the effects of cloud remains one of the main areas of uncertainty in the numerical simulation of climate change. The computed changes in cloud amount and consequent cloud radiative feedbacks for a warmer climate have been investigated by many authors using general circulation models (GCMs) and other tools. In general, GCM results show that cloud processes play a key role in determining the sensitivity of climate to an external forcing. In comparing 19 GCMs, Cess et al. (1990) found that the global-average climate sensitivity of the models varied by about a factor of 3 , when measured by surface temperature changes, and that much of this difference was related to differences in cloud radiation parameterizations among the models. Senior and Mitchell (1993) tested four different cloud schemes with a version of the U.K. Meteorological Office atmospheric GCM. Schemes that included prognostic cloud water variables were more realistic in 
some respects than schemes that did not, although all model versions produced control climates that still showed marked differences from the observational data. The sensitivity of each of the versions to a doubling of $\mathrm{CO}_{2}$ was critically dependent on the scheme; when cloud was parameterized on relative humidity, a strong positive cloud radiation feedback was found, while when interactive cloud water was included, a negative feedback was found.

Furthermore, Senior and Mitchell (1993) found that there were substantial differences between the results of $\mathrm{CO}_{2}$ doubling experiments and those of inverse climate change experiments forced by prescribed changes in sea surface temperature. One motivation for the present study is to examine the model dependence of these results. If we were to test the same cloud schemes in a different GCM, the results might be different, because of differences in physical parameterizations other than cloud processes, for example. Additionally, nonlinear interactions between such processes might cause significant differences in the cloud distributions and the resulting radiation fields.

In the present study, we test five different cloud radiation schemes in the National Center for Atmospheric Research (NCAR) Community Climate Model Version 2 (CCM2). The schemes consist of the original CCM2 scheme (CCM2), a prognostic cloud water scheme (CW), a scheme with explicit cloud water path and fixed cloud droplet effective radius (CWRF), one with variable droplet effective radius for warm cloud only (CWRV), and one with variable droplet effective radius including ice phase cloud (CWRI). Brief descriptions of each scheme are presented in section 2 . In section 3 , a diagnostic method proposed by Zhang et al. (1994) using an off-line radiation calculation is briefly described. With this approach, we can examine the role of various physical processes in determining the total climate feedback. To investigate the sensitivity of each cloud radiation scheme, a $\pm 2 \mathrm{~K}$ globally constant sea surface temperature (SST) perturbation, in conjunction with a perpetual July simulation, is adopted as a surrogate climate change (Cess and Potter 1988; Cess et al. 1990; Zhang et al. 1994). As Cess and colleagues have pointed out, this procedure is in essence an inverse climate change simulation: rather than introducing an external forcing into the model-for example, doubling $\mathrm{CO}_{2}-$ and then letting the climate respond to this forcing, we instead prescribe the climate change and let the models in turn produce their respective forcings. To focus solely on atmospheric feedback processes, we have excluded the ice-albedo feedback by fixing the icelines - that is. SST in regions adjacent to sea ice is fixed at values appropriate to the present July conditiondisregarding the $\pm 2 \mathrm{~K}$ SST perturbation, as in the studies cited above.

Section 4 describes the model simulations of cloud and radiation fields of both the present climate and the SST-induced climate change, together with satellite- derived observational estimates of cloud radiative forcing fields from the Earth Radiation Budget Experiment (ERBE, e.g., Barkstrom 1984) narrow-field-of-view (NFOV) monthly mean radiation budget data (this is the so-called ERBE S-4 data). We set the solar declination and SST at mid-July conditions and have generated a 240-day perpetual July integration for each case. The final 60 days of each integration are examined for this study. We have fixed the temperature in the bottom two layers of the four-layer finite-heat-capacity soil model of the CCM 2 at the model's July climatological values, regardless of the SST setting, because the relaxation time of the bottom layer is about 5 yr (Zhang et al. 1994). This allows quick equilibration between the surface and the atmosphere. However, we retained the diurnal variation of solar insolation. The CCM2-simulated present climate shows good qualitative agreement with the observational data, but quantitatively there naturally are significant disagreements.

In section 5, we compare the cloud radiation parameterizations using a single-column diagnostic model, together with measurements from the Atmospheric Radiation Measurement (ARM) program and from the Tropical Ocean Global Atmosphere Combined OceanAtmosphere Response Experiment (TOGA COARE). Our conclusions are presented in section 6 .

An overall decrease in cloud amount in a simulated warmer climate, which is typical in GCM results, can' significantly reduce the infrared trapping (greenhouse effect). Hence, the earth can emit longwave radiation more efficiently; that is, the cloud change moderates the global warming (a negative feedback). But, at the same time, the incoming shortwave radiative forcings of the surface-atmosphere system may increase, because the decreases in cloud amount cause a reduction in solar radiation reflected by clouds (a positive feedback). Furthermore, cloud height feedbacks also produce a positive feedback in many models. If, in addition. we consider changes in the radiative properties of clouds, the above feedback mechanisms may become much more complicated. In this study, we have tested the effect of interactive radiative properties, especially microphysical cloud radiative properties. on the simulated climate change. Somerville and Remer (1984) hypothesized that a warmer atmosphere would lead to increased average cloud water content, even if there is little change in average cloud cover. Using a simple radiative-convective model, they found that a warming produced optically thicker and so more reflective cloud, tending to cool the surface-atmosphere system by providing a negative shortwave feedback on the climate change. In this study we have tested this hypothesis using a GCM and have obtained results consistent with those of Somerville and Remer.

\section{Model description}

a. Original CCM2 scheme (CCM2)

There are two standard versions of $\mathrm{CCM}_{2} 2$ in terms of horizontal resolution: a $\mathrm{T}+2$ version (approximately 
equivalent to $2.8^{\circ}$ lat $\times 2.8^{\circ}$ long) and an $R 15$ version $\left(4.5^{\circ}\right.$ lat $\times 7.5^{\circ}$ long). In the vertical, there are 18 levels in both the T42 and the R15 versions, with a top at $2.917 \mathrm{mb}$. In this study, we use the lower resolution version (R15) for economy.

The scheme for predicting cloud fraction in CCM2 is based on the algorithm used in the operational ECMWF model (Slingo 1987), to which some modifications have been made (Hack et al. 1993). Layer cloud fraction depends on relative humidity, vertical motion and static stability. Some of the major changes from the Slingo (1987) formulation are the following: clouds are allowed to form in any tropospheric layer, except the layer nearest the surface; low-level clouds do not form unless the vertical velocity is upward; and the relative humidity thresholds for mid- and upper-level clouds are functions of atmospheric stability. However, we have eliminated the constraint on cloud-top height of the original CCM2 scheme.

The convective cloud water content is explicitly estimated in the CCM2 algorithm, during the course of computing convective rain rate, but there is no explicit cloud water estimation for layer clouds (Hack 1994). Therefore, the radiative properties of clouds, for both solar and terrestrial radiation, are calculated separately in CCM2 using cloud water paths (CWP), which are prescribed as a function of latitude, cloud height, and cloud-layer thickness.

The computation of large-scale precipitation in CCM2 is based on an adjustment process. If the atmosphere is stable but supersaturated, the moisture field is adjusted to be saturated, and the temperature field is simultaneously adjusted to reflect the heating due to the release of latent heat. The corresponding stable precipitation rate is computed accordingly. See Hack et al. (1993) for details.

\section{b. Cloud water scheme ( $C W)$}

The cloud water scheme is based on that of Smith (1990), as is that of Senior and Mitchell (1993). The scheme introduces an additional prognostic variable representing layer cloud water content $\left(q_{c}\right)$. Then,

$$
q_{w}=q+q_{c}
$$

where $q_{w}$ and $q$ are the total water content and specific humidity, respectively. Here, $q_{w}$ is increased by convergence of water vapor due to convection or largescale advection and by evaporation of precipitation, and it is reduced by precipitation. In this study. the largescale advection and the boundary layer vertical mixing of $q$. are ignored for simplicity.

The calculation of cloud amount and cloud water content uses cloud distribution concepts: that is. a statistical distribution of cloud-conserved variables about their grid-box mean is assumed. In the mean, the amount of cloud and its water content clearly depend on the difference between $q_{w}$ and the saturation specific humidity, while the statistics of the local deviation from the mean or sub-grid-scale fluctuation, say $s$, are defined by a prescribed distribution function, say $G(s)$. The mean cloud fraction is the fraction of the grid box with cloud water content greater than zero, and the mean cloud water is the integral of the local cloud water content. For this study we adopt $G(s)$ as a simple symmetric triangular function, as used by Smith (1990). Unlike models without a prognostic cloud water variable, in which all condensed water is precipitated. a model with cloud water requires a parameterization of the depletion of cloud water due to precipitation. We use a scheme based on that of Sundqvist (1981). but frozen water is assumed to precipitate with a specified fall speed as soon as it forms.

The source code of this scheme is extracted from the U.K. Meteorological Office Unified Model. All the parameter values are taken to be identical to those in the Unified Model, except the values of critical relative humidity for determining cloud fraction and the cloud water content. These critical values were retuned for realism of the control climate from 0.925 for the boundary layer and 0.85 for the rest of layers to 0.99 and 0.95 , respectively. The radiative properties of cloud for this scheme are prescribed and are the same as those of CCM2.

\section{c. Interactive cloud radiative properties scheme: \\ Fixed effective cloud droplet radius (CWRF)}

The radiative properties of clouds are assumed to depend on their water content, the phase of the water and the distribution of water droplet or ice particle sizes. In this scheme we attempt to compute the cloud water path explicitly in terms of cloud water content estimated from the cloud water scheme. The cloud water path, CWP, in units of $\mathrm{kg} \mathrm{m}^{-2}$ in each layer can be written as

$$
\mathrm{CWP}=\int \rho_{n} d z=\frac{q}{C} \rho_{u} \Delta z \text {. }
$$

where $\rho_{w}$ is the cloud water density $\left(\mathrm{kg} \mathrm{m}^{-3}\right), C$ is the cloud fraction, $q d C$ is the in-cloud water content. $\rho_{\text {: }}$ is air density, and $\Delta z$ is layer depth. Here, $q_{c}$ is the sum of convective cloud water and layer cloud water. For shortwave radiation, CWP is used to define the cloud extinction optical depth $\tau_{r}$ as

$$
\tau_{c}=\operatorname{CWP}\left(p+\frac{q}{r_{c}}\right) .
$$

where $p$ and $q$ are constants and $r_{e}$ is the effective radius of the cloud droplets (taken to be $10 \mu \mathrm{m}$ ). The above formula for $\tau_{c}$, as well as the cloud scattering and absorption parameterizations in the following section. are from Slingo (1989). Here, $\tau_{c}$ will in turn affect the transmissivity and reflectivity of both direct and diffuse solar radiation. A larger CWP for fixed $r_{r}$ implies an optically thicker cloud, and thus more reflection and less trans- 


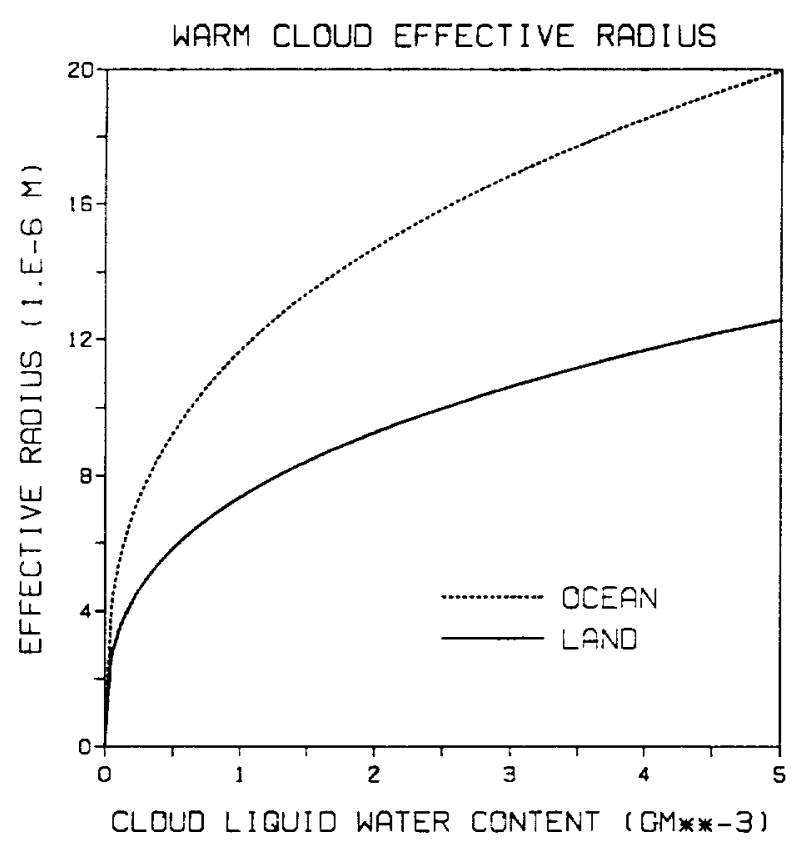

FiG. 1. Cloud liquid water content vs effective radius of warm cloud particle (after Bower et al. 1994).

mission of shortwave radiation. For longwave radiation, CWP is used to define the cloud emissivity as described below.

\section{d. Interactive cloud radiative properties scheme: Varying effective droplet radius for warm cloud only (CWRV)}

In addition to the dependence of cloud water path on cloud water content as in the case of CWRF, in this scheme we adopt a parameterization of the cloud droplet effective radius $\left(r_{s}\right)$ in terms of cloud liquid water content, as suggested by Bower et al. (1994)

$$
r_{e}=100\left(\mathrm{LWC} \times \frac{3}{4 \pi N}\right)^{1 / 3} .
$$

where the unit of $r$, is $\mu \mathrm{m}$, LWC is the liquid water content (in $\mathrm{gm}^{-3}$ ) predicted from the cloud water scheme, and $N$ is a fixed estimate of the droplet number concentration. taken as $150 \mathrm{~cm}^{-3}$ over the oceans and $600 \mathrm{~cm}^{-3}$ over the continents (see Fig. 1). However, for ice cloud, the effective radius is fixed at $10 \mu \mathrm{m}$, which is the same as the prescribed value of $r_{e}$ for the cases of CCM2. CW, and CWRF. Here we are using the numerical values of Bower et al. (1994). A wide range of other estimates can be found in the literature.

In addition to the dependence of the cloud extinction optical depth $\tau_{c}$ on $r_{\text {c }}$ as shown in (2), $r$, is employed to parameterize the cloud particle single-scattering albedo $\omega$ and the asymmetry parameter $g(-1$ to 1$)$ following Slingo (1989); that is,

$$
\begin{aligned}
\omega & =1-c-d r_{e} \\
g & =e+f r_{e},
\end{aligned}
$$

where $c, d, e$, and $f$ are positive constant coefficients. The variation of $r_{e}$ will affect shortwave radiation in the following manner. A larger $r_{e}$ for fixed CWP means fewer droplets and a smaller effective cross section, and hence a smaller $\tau_{c}$ from (2). Additionally, a larger $r_{\text {e }}$ implies more absorption of radiation transmitted through the droplet, and hence a smaller $\omega$ from (4). Finally, a larger $r$ implies more forward scattering, and hence a larger $g$ from (5).

Furthermore, in this scheme we adopt the same absorption coefficients for long wave emissivity as those of Senior and Mitchell (1993), who differentiate ice cloud from water cloud. The cloud emissivity $\epsilon$, in each model layer $k$, is defined in terms of CWP $\left(\mathrm{gm}^{-2}\right)$ as

$$
\epsilon(k)=1-e^{-a(W P(k)},
$$

where the factor $a$ is an absorption coefficient taken to be $0.13 \mathrm{~m}^{2} \mathrm{~g}^{-1}$ for water cloud and $0.065 \mathrm{~m}^{2} \mathrm{~g}^{-1}$ for ice cloud. Note that for the cases of CCM2, CW, and CWRF, $a$ is fixed at $0.1 \mathrm{~m}^{2} \mathrm{~g}^{-1}$. The cloud emissivity is accounted for by defining an effective cloud $C^{\prime}$,

$$
C^{\prime}(k)=\epsilon(k) C(k),
$$

where $C$ is cloud amount. Thus, larger CWP implies a larger emissivity, which in turn gives a larger effective cloud amount.

e. Interactive cloud radiative properties scheme: Varying effective droplet radius including ice cloud (CWRI)

In addition to the parameterization of warm cloud effective radius, in this scheme an attempt is made to parameterize the droplet effective radius of ice cloud in terms of cloud temperature from the observational study of Heymsfield and Platt (1984) as adapted by Suzuki et al. (1993) (see Fig. 2). We use

$$
r_{e}=0.71 T+61.29 \text {, }
$$

where $r_{e}$ is in $\mu \mathrm{m}$ and $T$ is in ${ }^{\circ} \mathrm{C}$. However, the upper and lower limits of $r$, are set at $40 \mu \mathrm{m}$ and $4 \mu \mathrm{m}$, respectively, since a limitation on the size of $r_{e}$ is needed for the formulation of cloud scattering and absorption parameterization used in (4) and (5). In the range where ice and liquid coexist, the following formula (Smith 1990) has been adopted to estimate $r_{e}$. First define

$$
f_{L}= \begin{cases}\frac{1}{6}[(T+15) / 5]= & \text { for }-15^{\circ} \mathrm{C}<T<-5^{\circ} \mathrm{C} \\ 1-\frac{1}{3}(T / 5)^{2} & \text { for }-5^{\circ} \mathrm{C} \leq T<0^{\circ} \mathrm{C} .\end{cases}
$$

The resulting $r_{e}$ in the mixed phase can then be written as 


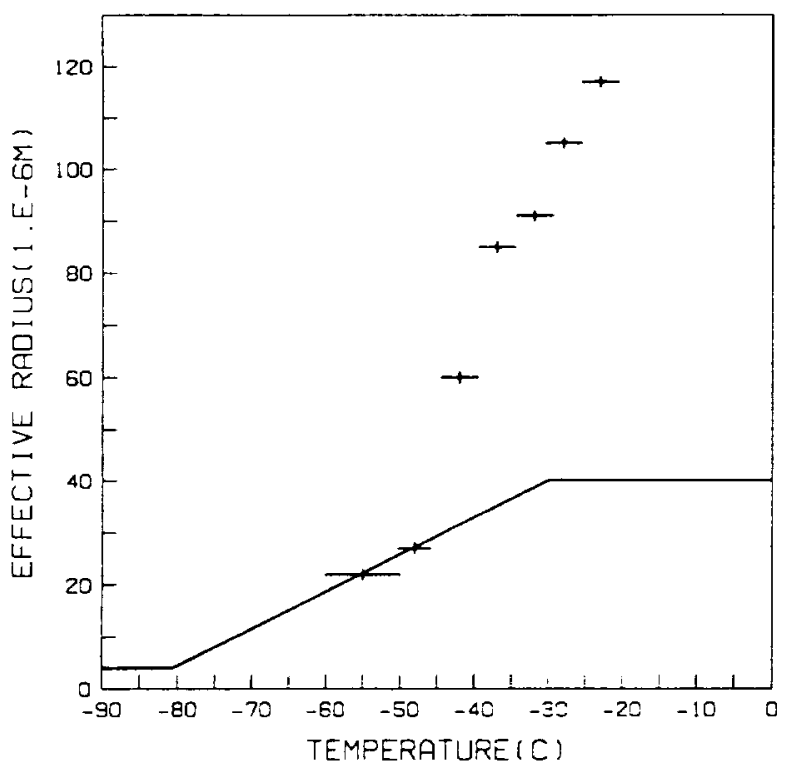

Fig. 2. Cloud temperature vs effective radius of ice cloud particle. Originally from Heymsfield and Platt (1984). adapted by Suzuki et al. (1993). Solid line shows our parameterization.

$$
r_{e}=f_{L} r_{e l}+\left(1-f_{L}\right) r_{e l} \text {. }
$$

where $r_{e t}$ is from (3) and $r_{e i}$ is from (8) for $-15^{\circ} \mathrm{C}<$ $T<0^{\circ} \mathrm{C}$.

The five parameterizations are summarized in Table 1.

\section{Diagnostic method}

To illustrate the link between cloud cover and the radiation budget, the concept of cloud radiative forcing (Ramanathan 1987; Ramanathan et al. 1989) is used here. Cloud radiative forcing (CF) is defined as the radiative impact of cloud upon the top-of-atmosphere (TOA) radiation budget and can be expressed as

$$
\mathrm{CF}=\left(Q-Q_{C}\right)-\left(F-F_{C}\right) .
$$

where $Q$ and $F$ represent the net incoming solar radiation and the outgoing longwave radiation at TOA, respectively, and the subscript $C$ denotes clear-sky fluxes. Hence CF is the net cooling or heating of the earthatmosphere system due to clouds. Here. CF can be separated into its shortwave $\left(\mathrm{CF}_{\mathrm{SW}}=Q-Q_{\mathrm{C}}\right)$ and longwave $\left(\mathrm{CF}_{\mathrm{L}, \mathrm{W}}=F_{C}-F\right)$ components. In general $\mathrm{CF}_{\mathrm{Sw}}$ is negative because of the reflectance effect of cloud on incoming shortwave radiation; that is, $Q<Q_{C}$. However, when clouds are present, the atmospheric column radiates less thermal energy into space than would clear skies, because the effective radiating altitude is generally greater-that is. $F_{C}>F$-so that $C_{1 w}>0$.

To investigate the sensitivity of each scheme to "global warming, " a \pm 2 K SST perturbation is adopted as a surrogate climate change (Cess and Potter 1988; Cess et al. 1990; Zhang et al. 1994). Hereafter, "change" or $\Delta$ implies the change of a quantity arising
TABLE 1. Summary of parameterizations for the tive model versions

\begin{tabular}{lccc}
\hline \hline & $\begin{array}{c}\text { Layer cloud } \\
\text { water }\end{array}$ & $\begin{array}{c}\text { Cloud optical } \\
\text { thickness }\end{array}$ & Effective radius \\
\hline CCM2 & $\begin{array}{c}\text { none } \\
\text { explicit }\end{array}$ & $\begin{array}{c}\text { specified } \\
\text { specified }\end{array}$ & not applicable \\
CWRF & explicit & calculated & not applicable \\
CWRV & explicit & calculated & varying (warm cloud only) \\
CWRI & explicit & calculated varying (including ice cloud) \\
\hline
\end{tabular}

from this type of simulation-that is, the value of the quantity in the SST $+2 \mathrm{~K}$ case minus the value of the quantity in the SST $-2 \mathrm{~K}$ case.

To isolate the effect of cloud feedback from that of other feedbacks, we adopt a method suggested by Zhang et al. (1994). The $\Delta F$ due to a climate change can be decomposed into the contributions from variations of temperature, water vapor, cloud, etc.; that is,

$$
\Delta F=\Delta F_{T}+\Delta F_{q}+\Delta F_{\mathrm{CL}}+\ldots+R_{e},
$$

where the subscripts $T, q$, and CL denote temperature, water vapor, and cloud, respectively, and $R_{e}$ is the residual term. The shortwave components can be defined similarly. Therefore, the changes of cloud radiative forcings from shortwave $\left(\Delta C F_{S W}\right)$, longwave $\left(\Delta C F_{L W}\right)$, and net $(\triangle C F)$ radiative effects, due to the simulated climate change, can be expressed as

$$
\begin{aligned}
\Delta \mathrm{CF}_{\mathrm{sW}} & =\Delta Q_{\mathrm{CL}} \\
\Delta \mathrm{CF}_{\mathrm{LW}} & =-\Delta F_{\mathrm{CL}} \\
\Delta \mathrm{CF} & =\Delta Q_{\mathrm{CL}}-\Delta F_{\mathrm{CL}} .
\end{aligned}
$$

In the computational procedure, state variables from the $\Delta S S T=-2 \mathrm{~K}$ experiment are saved as $\left(X_{k} . k=1\right.$, $2, \ldots)$ and state variables from the $\Delta S S T=+2 \mathrm{~K}$ experiment as $\left(X_{k}+\Delta X_{k}, k=1,2, \ldots\right)$. Off-line radiation calculations are performed to obtain $\lrcorner F_{X_{i}}$ $\left[=F\left(X_{1}, X_{2}, \ldots, X_{k}+\Delta X_{k}, \ldots\right)-F\left(X_{1}, X_{2}, \ldots, X_{k}\right.\right.$, $\ldots)]$ and $\Delta Q_{X_{k}}\left[=Q\left(X_{1}, X_{2}, \ldots, X_{k}+1 X_{k}, \ldots\right)-\right.$ $\left.Q\left(X_{1}, X_{2}, \ldots, X_{k}, \ldots\right)\right]$ at each grid point. A total of 240 fields, obtained by sampling instantaneously every 6 simulated hours over a total of 60 simulated days. are used in this study, in view of the calculated magnitude of differences in radiative fluxes between the simulated atmospheric states sampled hourly and the instantaneous fields. The partial feedbacks from cloud are attributed to variations of both cloud fraction and cloud microphysical properties, such as cloud water path and cloud droplet effective radius. Our sampling strategy is method 4 of Zhang et al. (1994).

This diagnostic method of off-line radiation calculation has also been applied to the investigation of the partial cloud radiative forcing of high, middle, and low cloud of the simulated present climate, which will be discussed below. 
TABLE 2. Radiation budget and cloud radiative forcing ( $\mathrm{W} \mathrm{m}^{-2}$ ) for ERBE observations and the five model versions. See text for definitions.

\begin{tabular}{lrrrrrr}
\hline \hline & ERBE & CCM2 & CW & CWRF & CWRV & CWRI \\
\hline$Q$ & 231.2 & 243.3 & 236.6 & 232.5 & 222.8 & 235.6 \\
$Q_{C}$ & 277.4 & 288.1 & 287.9 & 287.9 & 287.7 & 287.8 \\
$F$ & 238.3 & 246.1 & 233.0 & 240.3 & 243.2 & 244.6 \\
$F_{C}$ & 266.6 & 275.3 & 273.4 & 273.7 & 272.6 & 273.4 \\
$\mathrm{CF}_{\text {SW }}$ & -46.2 & -44.8 & -51.3 & -55.3 & -64.9 & -52.3 \\
$\mathrm{CF}_{\mathrm{LW}}$ & 28.3 & 29.2 & 40.4 & 33.4 & 29.4 & 28.8 \\
$\mathrm{CF}$ & -17.9 & -15.6 & -10.9 & -21.9 & -35.5 & -23.4 \\
\hline
\end{tabular}

\section{Model simulations}

\section{a. Present climate}

In Table 2, the global mean simulated and observed cloud radiative forcings are summarized. All the cases show negative net cloud forcing; that is, cloud has a cooling effect on the earth-atmosphere system. The discrepancies between ERBE observations and the model results arise from both cloudy-sky and clear-sky fluxes. For the resulting global mean cloud radiative forcing, the reasonable agreement between ERBE and CCM2 is noteworthy.

The simulated radiation budget may be explained in terms of the variables listed in Table 3, which summarizes the global mean values of three modelgenerated variables: total fractional cloud coverage, vertically integrated cloud water path, and effective cloud droplet radius.

For the estimation of the global mean effective radius, only grid points where the fraction is not zero are counted. For the cases without interactive cloud radiative properties (CCM2 and CW), the effects of cloud on the radiation budget and the consequent cloud radiative forcing are mainly attributable to the cloud fractional coverage. If we compare CCM2 and $\mathrm{CW}$, the smaller cloud fraction of $\mathrm{CCM} 2$, compared to that of $\mathrm{CW}$, simply explains the larger values of both $Q$ and $F$ of CCM2, compared to those of $\mathrm{CW}$. However. for the cases with variable cloud radiative properties (CWRF, CWRV, and CWRI), we must invoke additional variables to interpret the results. The differences in $Q$ for the cases of CWRF, CWRV, and CWRI. where the total cloud fractions are not much different. may be explained by the differences

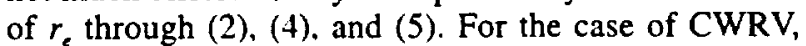
the smallest $r$, results in the smallest $Q$, and for the case of CWRI, the opposite is true; that is, a larger $r_{e}$ implies a smaller optical depth from (2), and a smaller particle scattering albedo from (4), which leads to larger shortwave fluxes. For longwave radiation, we notice that $F$ depends on cloud water path, if cloud fractional coverages are comparable; that is, a larger cloud water path implies a larger cloud emissivity from (6), and consequently a smaller $F$.

Figure 3 shows the zonal mean distribution of total cloud fraction for each case. CCM2 produces the small-
TABLE 3. Global mean total cloud, verically integrated cloud water path, and effective cloud droplet radius for the five model versions.

\begin{tabular}{lrcccc}
\hline & CCM2 & CW & CWRF & CWRV & CWRI \\
\hline Cloud $(\%)$ & 55.4 & 63.8 & 66.1 & 66.1 & 65.5 \\
Cloud water path $\left(\mathrm{gm}^{-2}\right)$ & 403.5 & 434.4 & 193.6 & 189.1 & 185.8 \\
Effective radius $(\mu \mathrm{m})$ & 10.00 & 10.00 & 10.00 & 9.67 & 11.31 \\
\hline
\end{tabular}

est cloud fraction at virtually every latitude. Figure 4 shows the zonal mean distribution of shortwave and longwave radiation and the associated cloud radiative forcings for the simulated fields and the ERBE data. The zonal mean distribution of the resulting net radiative forcing $C F$ is shown in Fig. 5. It is obvious from these figures that the reasonable agreement in global mean cloud radiative forcing (Table 2) between ERBE and CCM2 is largely due to canceling effects at different latitudes. For the cases of CWRF, CWRV, and CWRI. in which cloud radiative properties are explicitly parameterized, a sizeable improvement over CCM 2 and $\mathrm{CW}$, in which cloud radiative properties are specified, is seen in $Q$ and $F$ in the middle latitudes of the Northern Hemisphere.

Figures 6,7 , and 8 depict the height-latitude cross sections of cloud fraction in percentages, cloud water path in $\mathrm{gm}^{-2}$, and cloud droplet effective radius in $\mu \mathrm{m}$, respectively. In Fig. 6 we show only the cases of CCM2 and CWRF since differences in the distributions of cloud fraction among CW, CWRF, CWRV, and CWRI are barely distinguishable. This is true for Fig. 7 as well, where we show only the cases of CCM2 and CWRI. The cloud water paths of CCM2 and CW, in which those are specified in terms of height and layer thickness, are virtually identical to one another, and those of CWRF, CWRV, and CWRI, in which the same formula for cloud water path is applied, are also almost indistinguishable

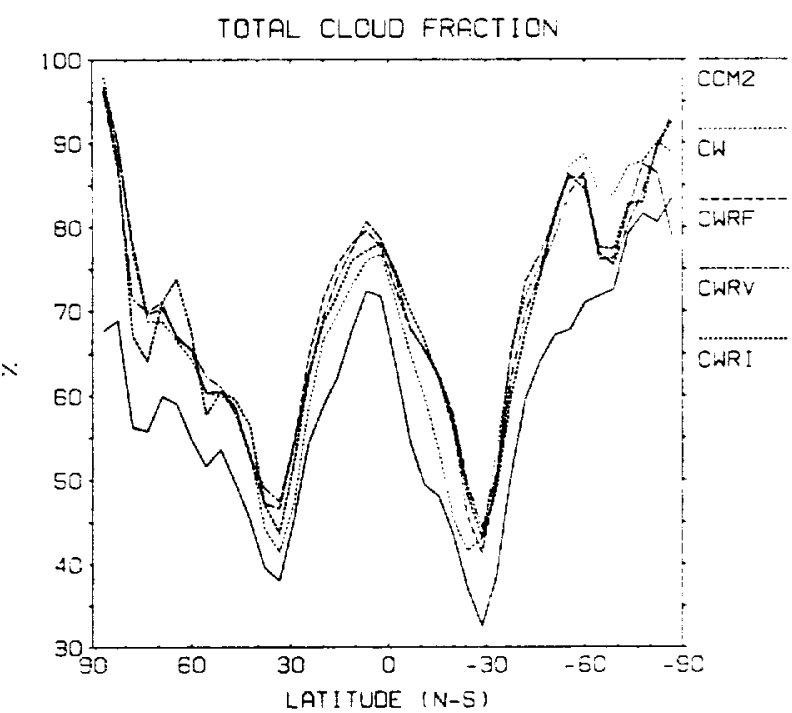

Fic. 3. Zonally averaged total cloud fractions in percents from 60-day perpetual July simulations. 

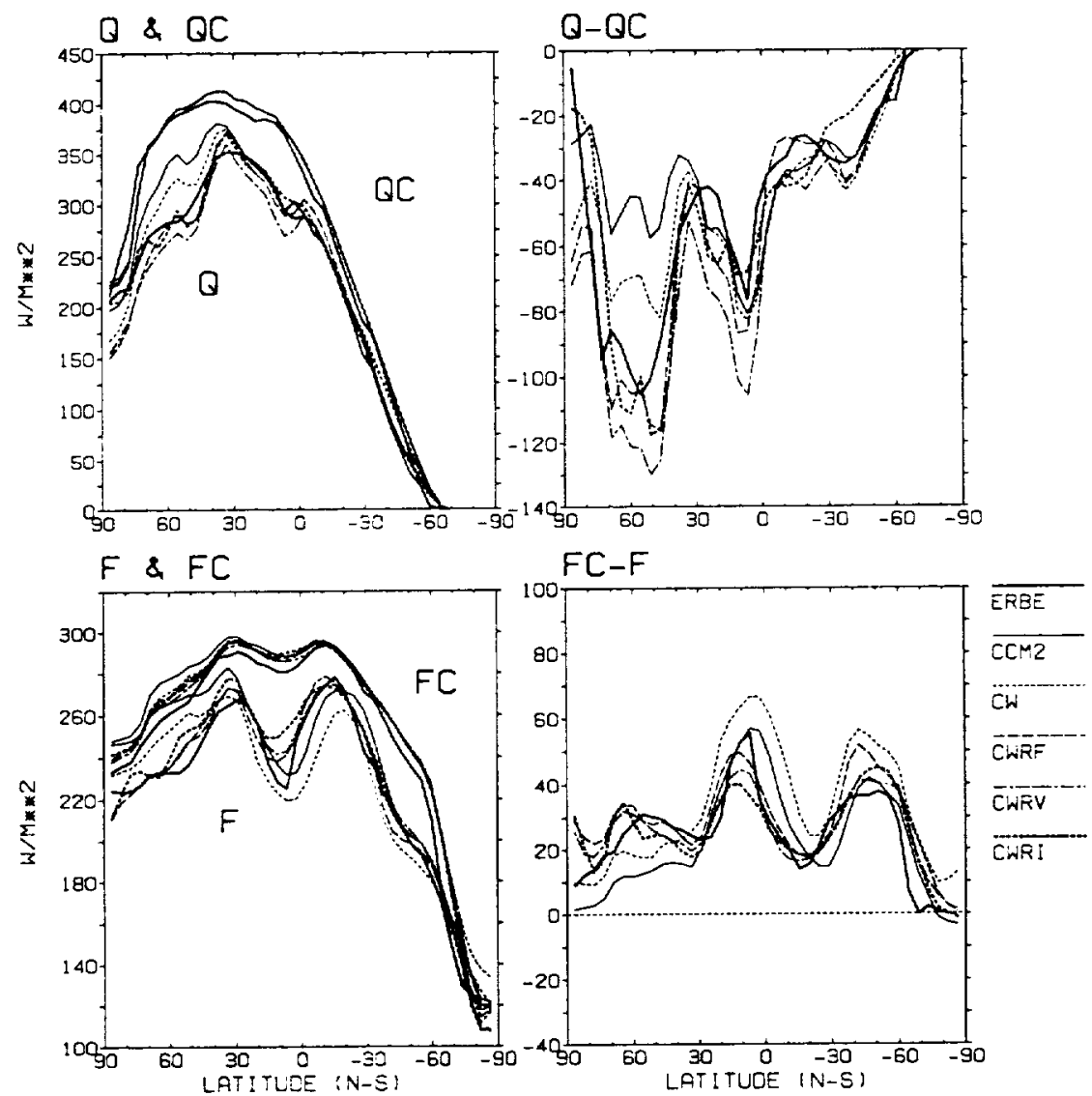

FiG. 4. Zonally averaged shortwave $(Q)$ and longwave $(F)$ radiation fluxes at the top of the atmosphere, their clear-sky components $\left(Q_{c}\right.$ and $\left.F_{c}\right)$, and the resulting shortwave and longwave cloud radiative forcings $\left(Q-Q_{c}\right.$ and $F_{c}-F$, respectively) from 60-day perpetual July simulations and the ERBE observational data for July 1985-88.

from one another. The distributions of effective radius of CWRV and CWRI are shown in Fig. 8. bearing in mind that $\mathrm{CCM} 2, \mathrm{CW}$, and $\mathrm{CWRF}$ have a fixed effective radius of $10 \mu \mathrm{m}$. In Fig. 8, we easily notice the effect of the ice cloud effective radius parameterization of CWRI; in the regions of warm cloud, there is little difference between the two models in the effective radius, while for the regions of ice cloud, the effective radius of CWRI is bigger than that of CWRV due to the temperature-dependent ice cloud effective radius parameterization of (8).

To investigate the height-dependence of cloud radiative forcing, we utilize the diagnostic method of offline radiation calculation. For this purpose. we define clouds above $400 \mathrm{mb}$ as high cloud, between 400 and $700 \mathrm{mb}$ as middle cloud, and below $700 \mathrm{mb}$ as low cloud. Figure 9 summarizes the results. For the shortwave forcing, the total forcing is mostly from the optically thick (large CWP) low cloud, while for the longwave forcing, it is mostly from the high cloud, as noted in other studies (e.g., Senior and Mitchell 1993). In terms of net cloud radiative forcing, the effect of high cloud is positive, and that of middle and low clouds is negative, giving a net negative cloud forcing. Note that there is a slight difference in the estimations of total cloud forcing between Fig. 9 and Table 2, since the former is estimated from the off-line radiation calculation, while that of Table 2 is from the model-simulated fields. Also note that the total forcing is not the same as the sum of the forcings from high, middle, and low cloud, since the assumption of random overlapping in the vertical direction emphasizes the highly nonlinear relationship between the total radiative forcing and the separate forcings, as also pointed out by Zhang et al. (1994).

\section{b. Sea surface temperature fuctuation experiments}

Table 4 summarizes the global means of feedbacks including partial contributions from cloud, water vapor. and temperature for each case. "FULL" denotes the estimation from the hourly averaged simulation, while "SUM" denotes the sum of partial terms (see also Fig. 10). Figure 11 shows the zonal mean changes in radiative fluxes due to the $\Delta$ SST climate change. The differences between the sum of the partial terms and the 


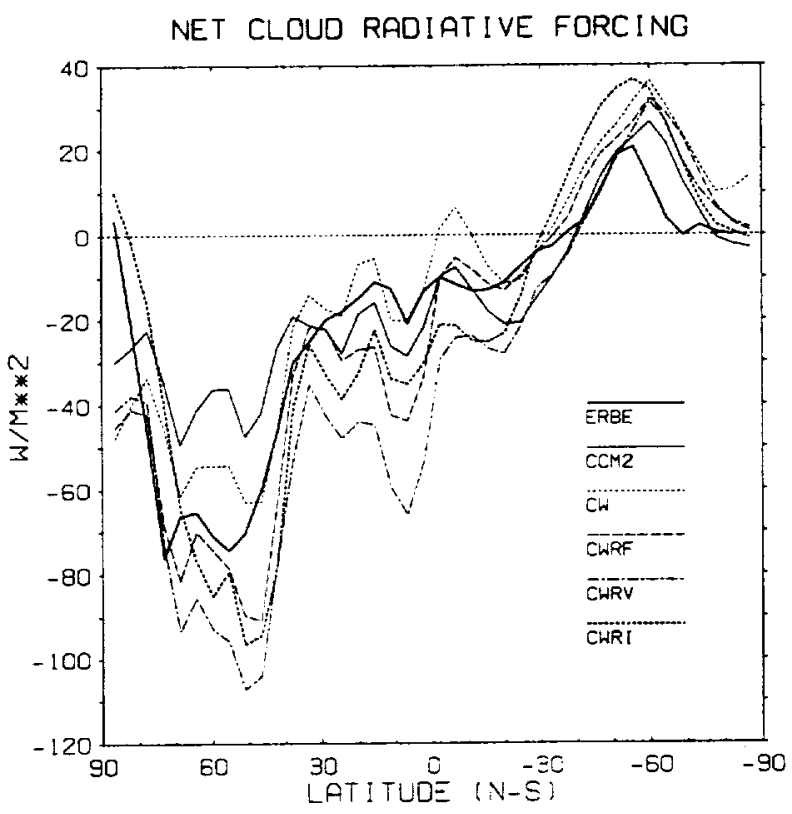

FIG. 5. Zonally averaged net cloud radiative forcings from 60-day perpetual July simulations and the ERBE observational data for July 1985-88.

simulated variation are indeed small, indicating that the variations of radiative fluxes are almost linear for this climate change of about $\Delta T=4 \mathrm{~K}$. For the changes in shortwave forcing, most of the variation is due to the changes in cloud, but the contribution from changes in water vapor, resulting from the increase of absolute humidity in the warmer climate, are also noticeable. There is no contribution in $\Delta Q$ from the changes in temperature, as expected. For the changes in longwave forcing, the water vapor greenhouse effect is apparent in terms of the reduction in $F_{q}$. The sum of $\Delta F_{T}$ and $\Delta F_{q}$, which expresses the net effect of temperature and water vapor on the longwave flux, is positive; that is, there is a net radiative loss of energy due to feedbacks involving these two factors. The thin solid lines in Fig. 11 represent the zonal mean distribution of cloud radiative forcing. Table 5 denotes the global mean cloud radiative forcing based on data from Table 4, and for comparison purposes, the estimates from the method using (10) are denoted by (old). It is noteworthy that the signs of cloud radiative feedbacks are different between the schemes with specified cloud radiative properties-that is, CCM2 and $\mathrm{CW}$-and the schemes with interactive radiative properties-that is, CWRF, CWRV, and CWRI. For the cases of CCM2, CW, and CWRI, the net cloud radiative feedback is negative-that is, cloud moderates the global warming, while for the cases of CWRF and CWRV, the opposite is true.

A useful measure of the cloud radiative feedback is the quantity $\triangle \mathrm{CRF} / G$, which is the change in cloud radiative forcing normalized by the direct radiative forcing (e.g., Cess et al. 1996). When $\triangle C R F / G$ is unity, the direct radiative forcing is amplified by a factor of 2 ,
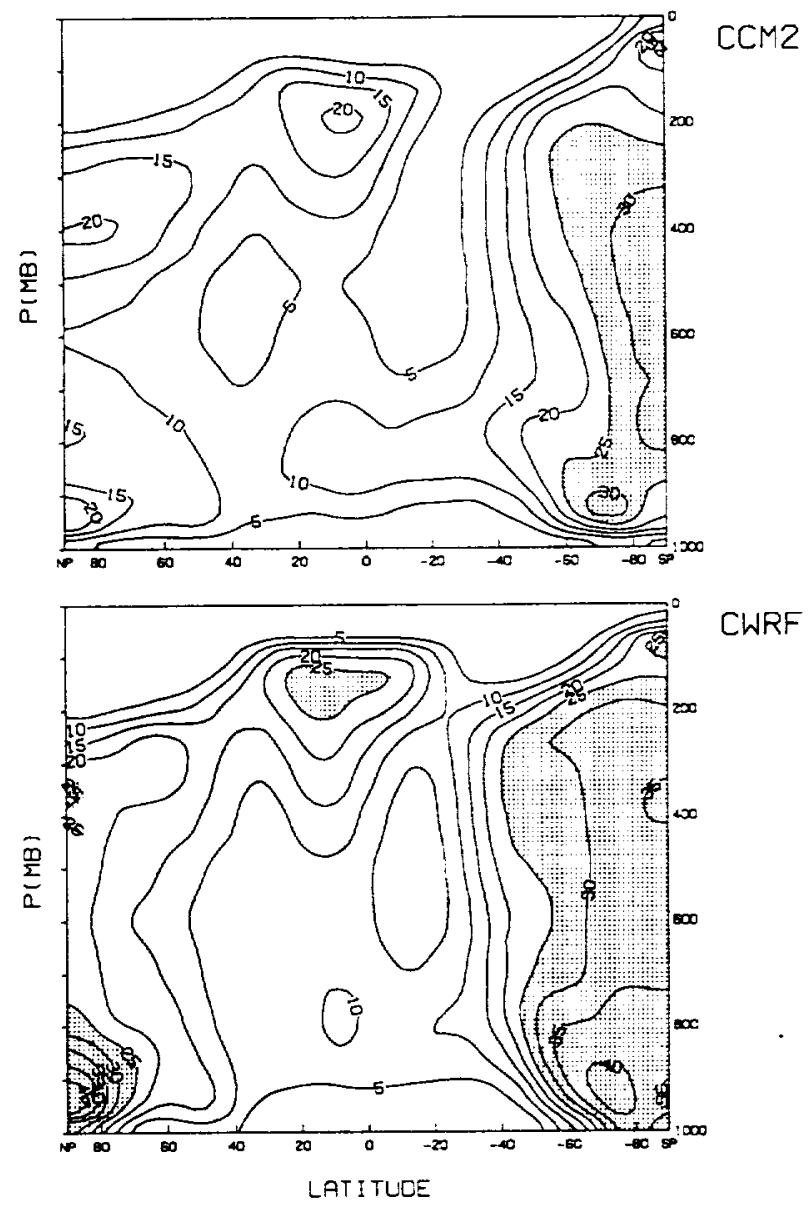

Fig. 6. Height-latitude cross section of cloud amount for $\mathrm{CCM} 2$ and CWRF from 60-day perpetual July simulations. Contours every $5 \%$; regions of over $25 \%$ are stippled.

that is, a twofold positive feedback. In terms of the variables in Table 4, $\Delta C R F / G$ is equivalent to $-\Delta(Q-$ $F)_{\mathrm{CL}} / \Delta(Q-F)_{\mathrm{FULL}}$. This quantity is shown in Table 4 , where it can be seen to vary from -0.18 to 0.32 . Thus, the range of cloud radiation parameterizations explored in these experiments yields feedbacks ranging from slightly negative to slightly positive on a global basis. Of course, the local effects of these feedbacks may be more significant than the global mean values, which are the focus of the present study.

Table 6 is similar to Table 3 except for the changes in the $\Delta S S T$ experiments. The positive $\Delta \mathrm{CF}_{\mathrm{sw}}$ for the cases of CCM2 and CW is simply related to the reduction of total cloud fraction. Similarly, the negative $\triangle \mathrm{CF}_{\mathrm{LW}}$ for the cases of CCM2 and $\mathrm{CW}$ is also related to the reduction of total effective cloud fraction. However, for the cases of CWRF. CWRV, and CWRI, the increase in CWP results in a positive $\Delta \mathrm{CF}_{\mathrm{LW}}$ even though the total cloud fraction decreases. For shortwave radiation, the negative $\triangle C F_{\mathrm{Sw}}$ for the case of $C W R F$ is due to the increase in CWP, which dominates over the effect of a decrease in total cloud fraction, while the 

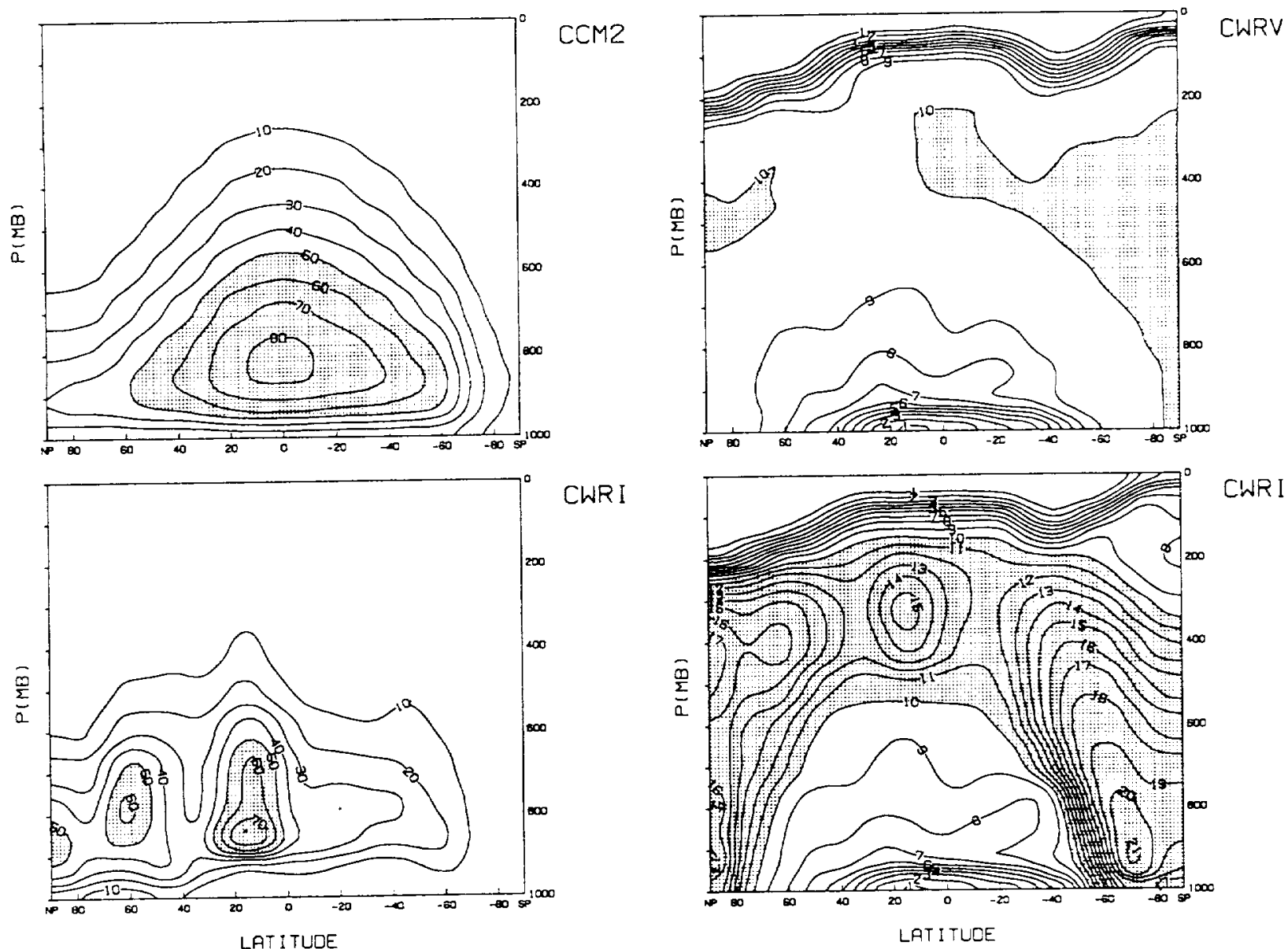

CWR I

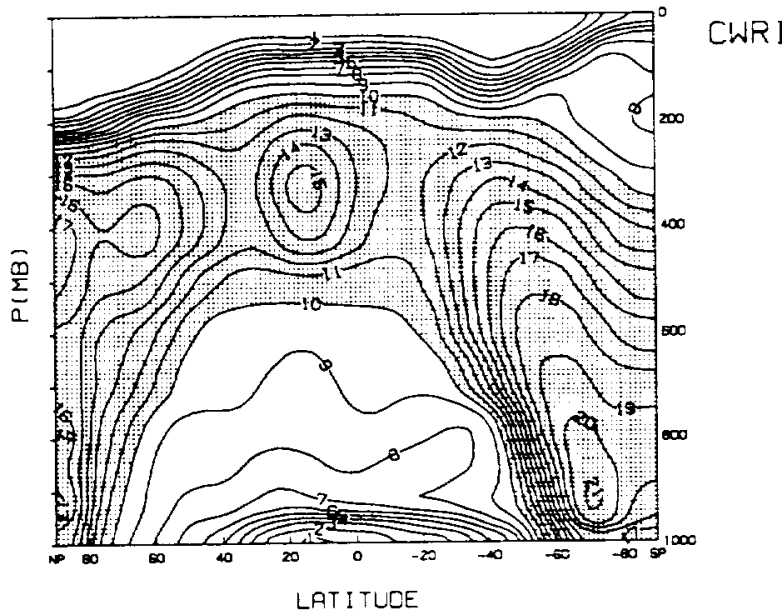

FIG. 7. Height-latitude cross section of cloud water path for CCM2 and CWRI from 60-day perpetual July simulations. Contours every $10 \mathrm{gm}^{-2}$; regions of over $50 \mathrm{gm}^{-2}$ are stippled.

negative $\Delta C F_{S W}$ for the cases of CWRV and CWRI is due to the combined effects of an increase in CWP and a decrease in $r_{\text {e }}$.

The literature contains conflicting estimates of the temperature dependence of cloud optical thickness. For a recent discussion, see Del Genio et al. (1996).

Figures 12,13 , and 14 are similar to Figs. 6, 7, and 8 except for the changes in the $J S S T$ experiments. In Fig. 12, the increase in high cloud at low latitudes and the decrease in middle-level cloud are common to all of the models, even though here we present only the cases of CCM2 and CWRF. The maximum in high cloud at low latitudes moves upward as the height of the tropopause increases, as found in previous numerical studies (e.g., Mitchell and Ingram 1992). In Fig. 13, the change in cloud water path of CCM2 is indeed negligible compared with that of CWRI, as also noted in Table 6. In Fig. 14, there is a large reduction in the cloud effective radius for the case of CWRI at middle latitudes, which is due to a decrease in the temperaturedependent effective radius of ice and mixed cloud - that

FiG. 8. Height-latitude cross section of cloud droplet effective radius for CWRV and CWRI from 60-day perpetual July simulations. Contours every $1 \mu \mathrm{m}$; regions of over $10 \mu \mathrm{m}$ are stippled.

is, to a change of state from ice (larger $r_{e}$ ) to liquid (smaller $r_{e}$ ).

Figure 15 is similar to Fig. 9. but again depicts the changes. The decrease in longwave forcing for the cases of CCM 2 and $\mathrm{CW}$ is mainly attributable to a decrease in high cloud fraction. However. for the shortwave feedback of CCM2, it is noteworthy that an increase in low cloud water path, even though its magnitude is small, results in a negative low cloud shortwave feedback. The increase in high cloud fraction for the cases of CWRF, CWRV, and CWRI results in a positive high cloud net radiative feedback. The smaller negative high cloud feedback in CWRI compared to CWRV may be ascribed to the combined effects of a smaller increase in high cloud fraction and a larger increase in cloud droplet effective radius. However. the decrease in middle cloud effective radius does not have much impact on the resulting middle cloud shortwave forcing. The shortwave cloud radiative feedback due to effective radius is much smaller than that of cloud water path. Even though the changes in low cloud amount and low cloud water path are apparent, the resulting change in low cloud long- 

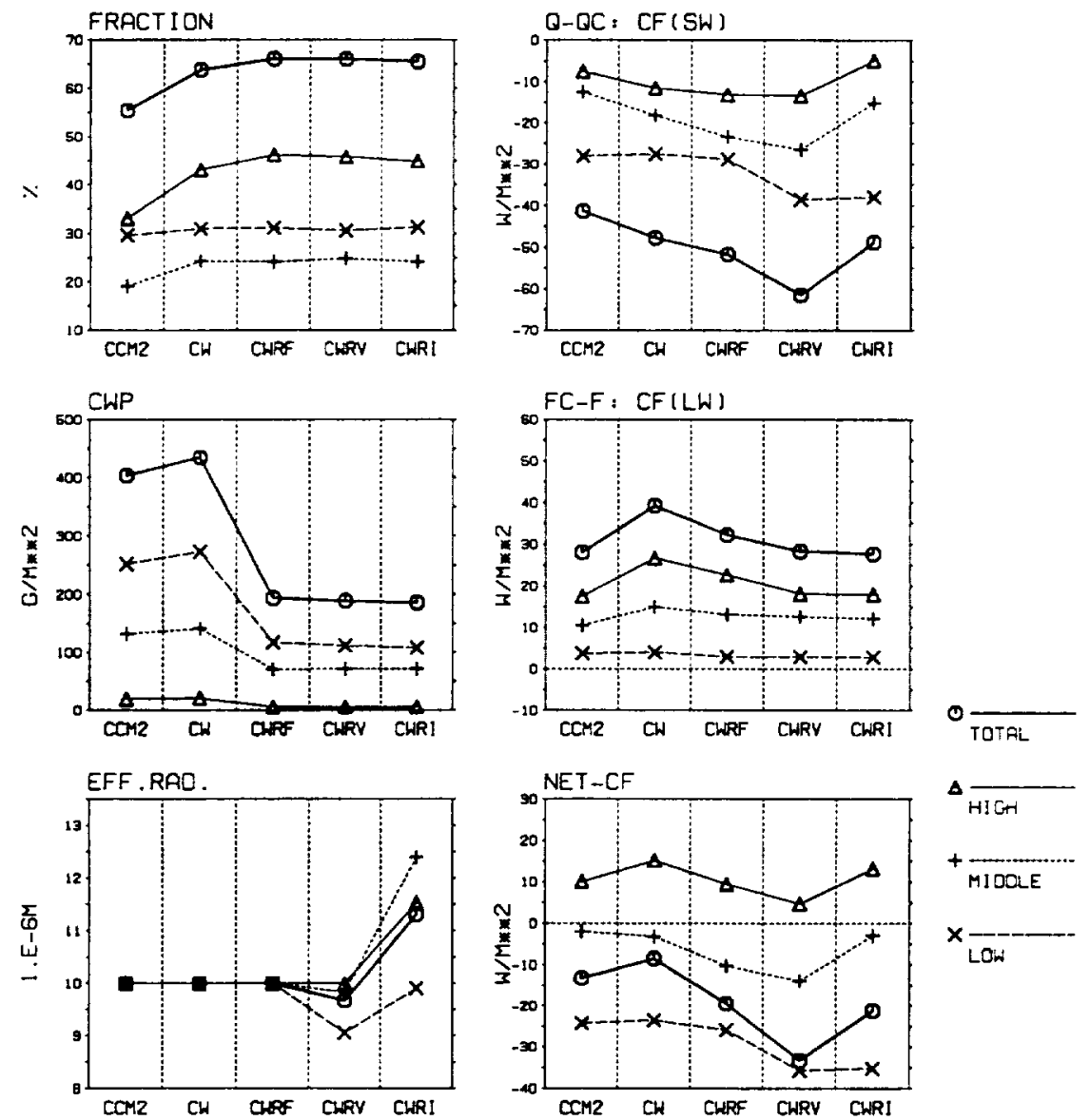

FIG. 9. Globally averaged total cloud fraction, vertically integrated cloud water path. cloud droplet effective radius, shortwave, longwave, and net cloud radiative forcings (denoted by $O$ ). Also shown are results from separate high, middle, and low cloud, denoted by $\Delta,+$, and $x$, respectively. All results are from 60 -day perpetual July simulations.

TABLE 4. Diagnostic analysis of feedbacks ( $\left.\mathrm{W} \mathrm{m}^{-3}\right)$. See text for definitions.

\begin{tabular}{lrrrrr}
\hline & CCM2 & \multicolumn{1}{c}{ CW } & CWRF & CWRV & CWRI \\
\hline$\Delta Q_{\text {FULL }}$ & 3.60 & 5.01 & -1.15 & -2.03 & -3.04 \\
$\Delta Q_{\text {sUM }}$ & 3.24 & 4.70 & -1.53 & -2.42 & -3.44 \\
$\Delta Q_{T}$ & 0.00 & 0.00 & 0.00 & 0.00 & 0.00 \\
$\Delta Q_{\triangleleft}$ & 0.83 & 0.68 & 0.68 & 0.83 & 0.71 \\
$\Delta Q_{\text {CL }}$ & 2.41 & 4.02 & -2.20 & -3.25 & -4.15 \\
$\Delta F_{\text {FULL }}$ & 14.82 & 13.44 & 4.95 & 5.69 & 5.83 \\
$\Delta F_{\text {SUM }}$ & 15.21 & 13.98 & 4.67 & 5.34 & 5.51 \\
$\Delta F_{r}$ & 18.19 & 15.88 & 17.30 & 17.12 & 17.11 \\
$\Delta F_{4}$ & -7.39 & -6.06 & -8.46 & -8.32 & -8.29 \\
$\Delta F_{\text {CL }}$ & 4.40 & 4.16 & -4.17 & -3.45 & -3.31 \\
$\Delta(Q-F)_{\text {FULL }}$ & -11.22 & -8.43 & -6.10 & -7.72 & -8.87 \\
$\Delta(Q-F)_{\text {SUM }}$ & -11.97 & -9.28 & -6.20 & -7.76 & -8.96 \\
$\Delta(Q-F)_{\tau}$ & -18.19 & -15.88 & -17.30 & -17.12 & -17.11 \\
$\Delta(Q-F)_{q}$ & 8.22 & 6.74 & 9.13 & 9.16 & 8.99 \\
$\Delta(Q-F)_{\text {CL }}$ & -1.99 & -0.14 & 1.96 & 0.20 & -0.84 \\
$\Delta \mathrm{CRF} / G$ & -0.18 & -0.02 & 0.32 & 0.03 & -0.09 \\
\hline
\end{tabular}

wave forcing is negligible. For the net change in cloud radiative forcings, we notice that high cloud produces a positive feedback, while low and middle clouds produce a negative feedback.

\section{Observational validation}

The preceding results demonstrate clearly that GCM simulations of climate sensitivity show a strong dependence on the way in which cloud radiation processes are parameterized. However, these model results cannot settle the question of which parameterizations are most realistic. Only a thorough comparison with observations can definitively show that one algorithm is superior to another. For example, it is not correct that the most physically comprehensive treatment is necessarily the best. It is one thing to design a scheme in which, for instance, radiative properties depend on a computed cloud water budget, and it is quite another to do so 

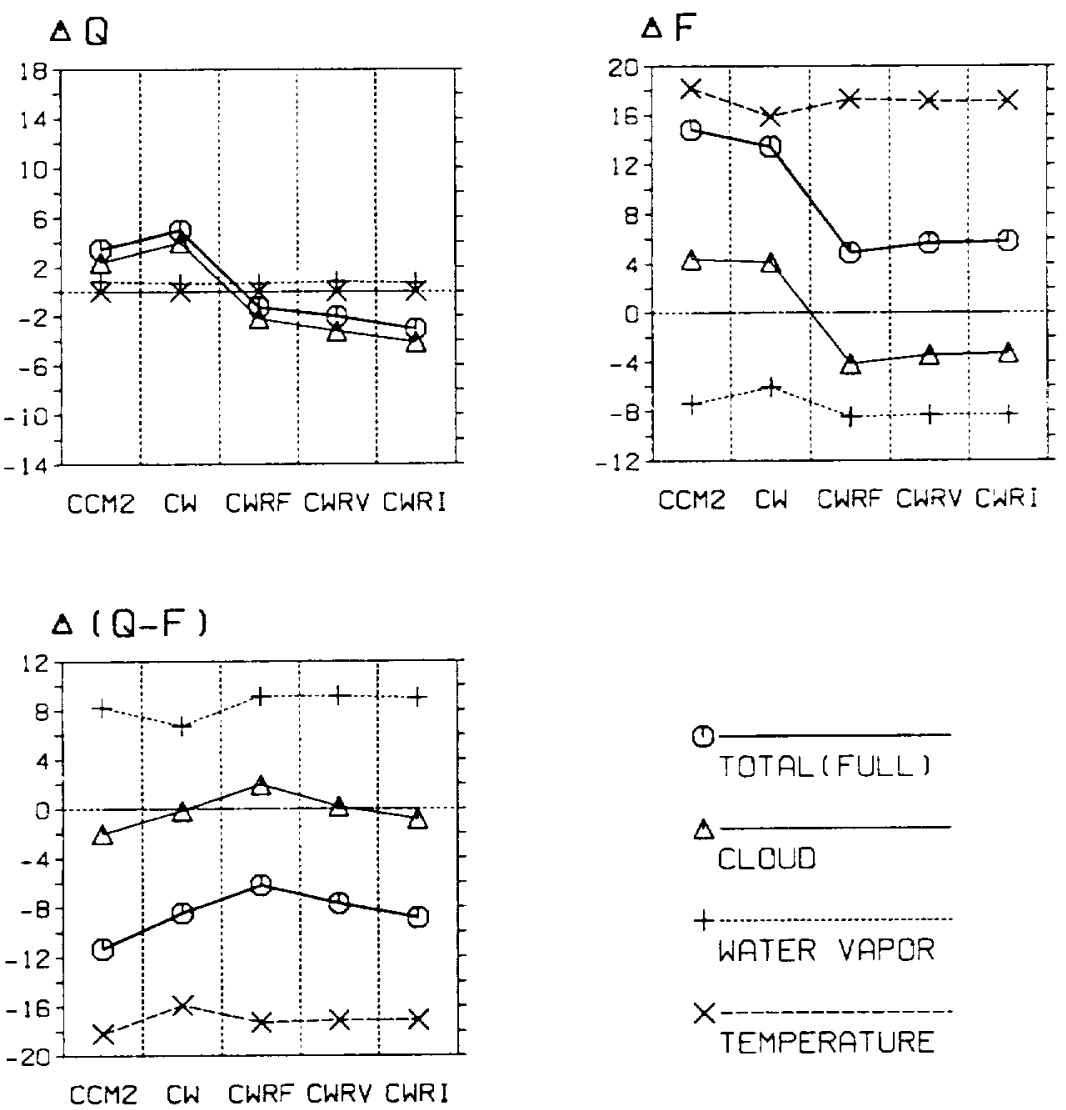

FIG. 10. Changes in globally averaged radiation $(O)$ and its partition into variations of cloud $(\triangle)$, water vapor $(+)$, and temperature $(X)$ due to $\Delta S S T= \pm 2 \mathrm{~K}$ experiments consisting of 60 -day perpetual July simulations.

realistically. Simply to assert that a given physical process is "included" or "taken into account" conveys nothing about whether the result is actually an improvement on a less ambitious scheme. For example, a simple prescription of cloud radiative properties may well be more appropriate than an overly complicated attempt to compute them based on questionable assumptions about cloud microphysics.

How then should one go about assessing the merits of parameterizations such as those described in section 2 ? There are many possible routes, and a comprehensive assessment is still a goal for the future. Nevertheless, recent progress has made it possible to begin the longneeded task of testing GCM algorithms empirically. In the present study, we have chosen to illustrate the potential of recent observational and theoretical advances by using a single-column model (SCM) in conjunction with measurements from two field programs, ARM and TOGA COARE. In this section, we describe the SCM and the field programs briefly, and we show results from using the SCM to validate the parameterizations used in our GCM tests against observations from the two field programs. Both these field programs provide intensive measurements of an atmospheric volume comparable to that overlying a single GCM horizontal grid cell. One program (ARM) provides data from a midcontinent, midlatitude region (the central plains of the United States). The other program (TOGA COARE) took place in the western tropical Pacific Ocean. Thus, we have independent data from two sites, which are dramatically different meteorologically. The theoretical tool for using these data to test GCM parameterizations is the SCM.

\section{a. SCM description}

The SCM is a computationally efficient and economical one-dimensional (vertical) model, resembling a single column of a general circulation model (GCM). The SCM is applied at a specific site having a horizontal extent typical of a GCM grid cell. Since the model is one-dimensional, the advective terms in the budget equations must be specified from observations or operational numerical weather prediction analyses.

The single-column model is diagnostic rather than prognostic. Its input is an initial state, plus the timedependent advection terms in the conservation equations, provided at all model layers. Its output is a complete heat and water budget for the study site, including temperature and moisture profiles, clouds and their ra- 


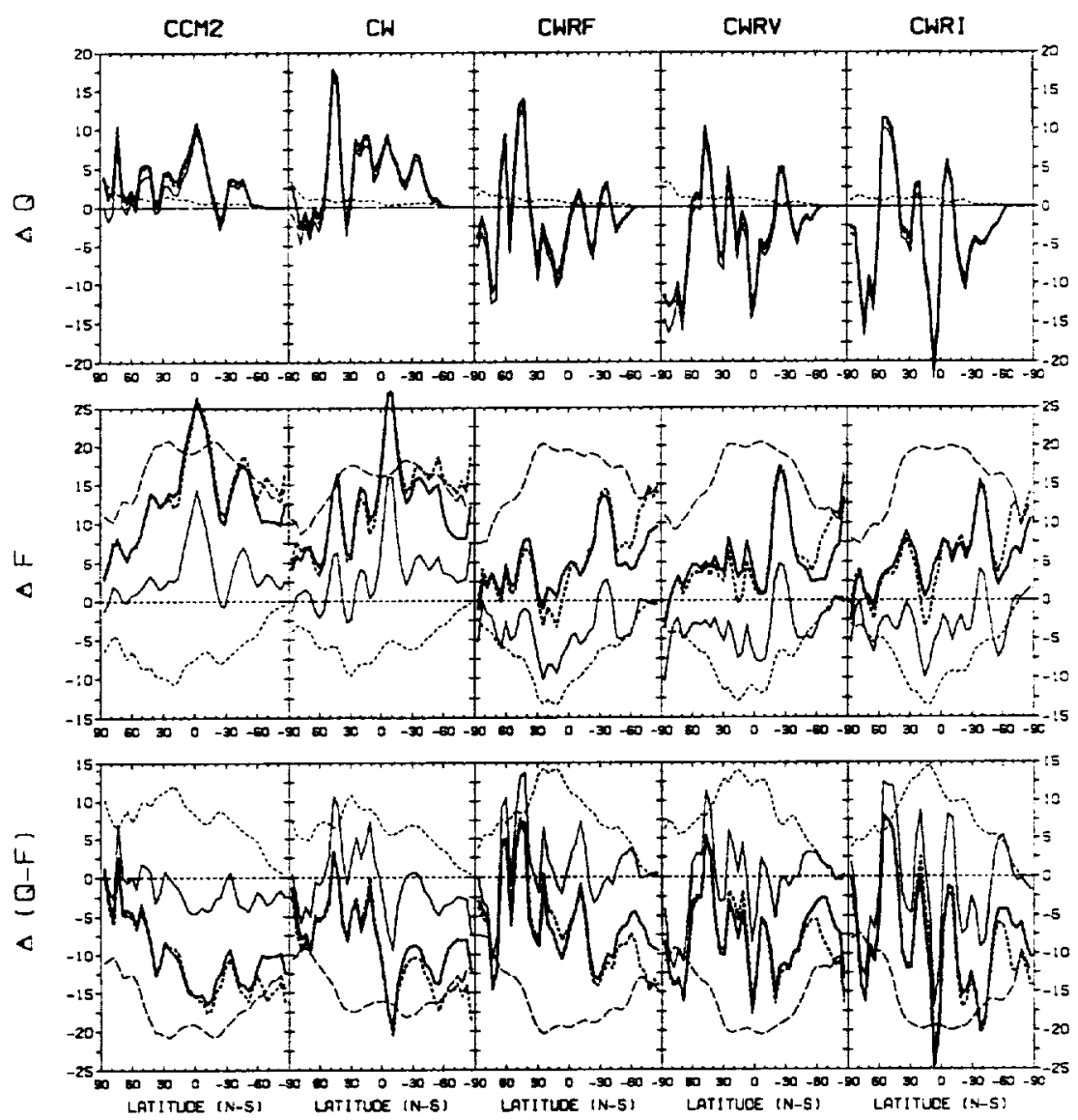

FIG. 11. Changes in zonally averaged variation of radiation and its partition into variations of temperature, water vapor, and cloud due to $\Delta S S T= \pm 2 \mathrm{~K}$ experiments consisting of 60-day perpetual July simulations; "FULL" (thick solid line), "SUM" (thick dotted line), "cloud" (thin solid lines), "water vapor" (thin dotted line), and "temperature" (thin dashed line).

diative properties, diabatic heating terms, surface energy balance components, and hydrologic cycle elements, all specified as functions of time. For a more complete discussion of SCMs, the reader is referred to Randall et al. (1996).

The present configuration of the single-column model has 16 vertical layers in the atmosphere and uses a time step of $7.5 \mathrm{~min}$. A diurnally varying solar signal dependent on the latitude and time of year is applied at the top of the model atmosphere using a solar constant of $1370 \mathrm{~W} \mathrm{~m}^{-2}$.

The SCM can be run in a "fully interactive" mode,

TABLE 5. Cloud radiative feedbacks ( $\mathrm{W} / \mathrm{m}$ ) for the five model versions. See text for definitions.

\begin{tabular}{lrrrrr}
\hline \hline & CCM2 & \multicolumn{1}{c}{ CW } & CWRF & CWRV & CWRI \\
\hline$\Delta C F_{\text {SW }}$ & 2.41 & 4.02 & -2.20 & -3.25 & -4.15 \\
$\Delta \mathrm{CF}_{\mathrm{LW}}$ & -4.40 & -4.16 & 4.17 & 3.45 & 3.31 \\
$\Delta \mathrm{CF}$ & -1.99 & -0.17 & 1.96 & 0.20 & -0.84 \\
$\Delta \mathrm{CF}_{\text {sw }}$ (old) & 2.97 & 4.57 & -1.75 & -2.48 & -3.50 \\
$\Delta \mathrm{CF}_{\mathrm{LW}}$ (old) & -6.08 & -5.36 & 2.45 & 1.86 & 1.54 \\
$\Delta \mathrm{CF}$ (old) & -3.11 & -0.79 & 0.70 & -0.62 & -1.96 \\
\hline
\end{tabular}

in which after being initialized, the SCM determines the temperature and humidity profiles at each time step using the heating and moistening rates calculated by the various model parameterizations. The main disadvantage of this mode is that accumulated model errors in the temperature and humidity profiles may affect the performance of the model parameterizations. Alternatively, the SCM can be run in the "semi-implicit" mode where the temperature and humidity profiles are specified from observational data at each time step. A drawback of this technique is that it may distort the atmospheric profiles that could affect significantly the heating

TABLE 6. Changes in global mean total cloud, vertically integrated cloud water path, and effective cloud droplet radius for the five model versions. See text for definitions.

\begin{tabular}{lccccc}
\hline & CCM2 & CW & CWRF & CWRV & CWRI \\
\hline $\begin{array}{l}\Delta \text { cloud (') } \\
\Delta \text { cloud water } \\
\text { path (gm }\end{array}$ & -1.33 & -1.59 & -0.50 & -1.08 & -1.04 \\
$\begin{array}{c}\Delta \text { effective } \\
\text { radius }(\mu \mathrm{m})\end{array}$ & 0.000061 & 0.000012 & 66.33 & 61.11 & 66.46 \\
\hline
\end{tabular}




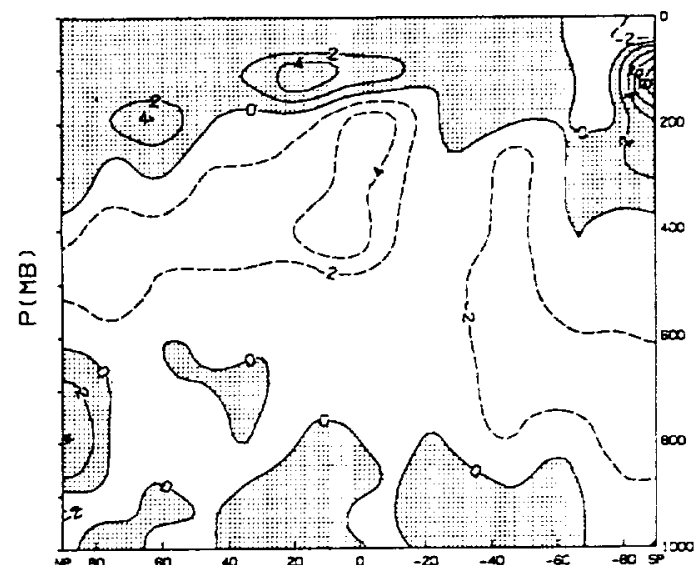

CCM2

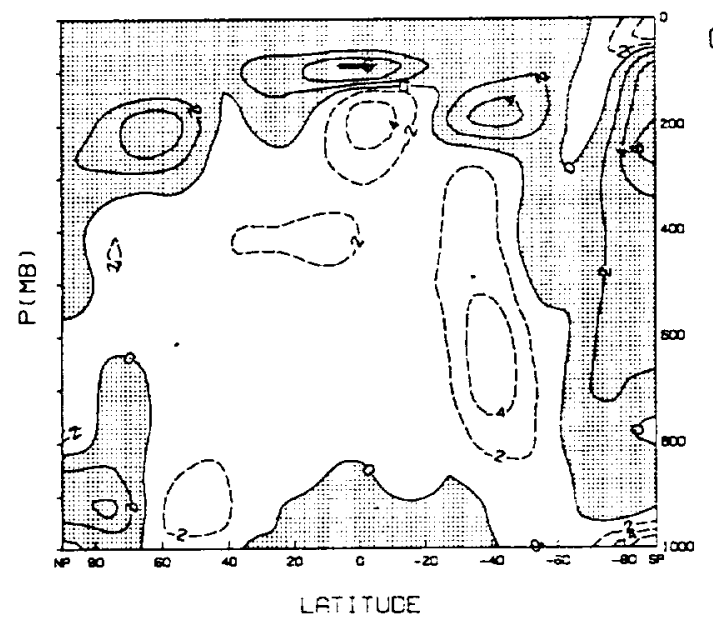

CWRF

FIG. 12. Heighi-latitude cross section of equilibrium changes in cloud amount for CCM 2 and CWRF from 60 -day perpetual July \pm 2 K SST simulations. Contours every $1 \%$ : regions of increase are stippled.

and moistening rates produced by the cumulus convection parameterization.

A compromise between these two modes is to operate the SCM in "relaxation mode" in which the temperature and humidity profiles are relaxed to the observed profiles using a specified time constant. $\beta$. A value of $\beta=$ $\infty$ represents the fully interactive mode. while a value of $\beta=\Delta t$, where $\Delta t$ is the model time step $(7.5 \mathrm{~min}$ in this study), represents the semi-implicit mode. In the SCM experiments described in this paper, a time constant of $\beta=24 \mathrm{~h}$ is used. The choice of $24 \mathrm{~h}$ helps to ensure that model errors in the temperature and humidity profiles remain small without seriously distorting the atmospheric profiles.

The SCM contains a full set of parameterizations of subgrid physical processes that are normally found in a modern GCM. In the SCM experiments that follow, the parameterizations used to determine the cloud properties are the same as in the five schemes CCM2, CW. CWRF, CWRV, and CWRI. The SCM does employ some physical parameterizations that differ from those used in
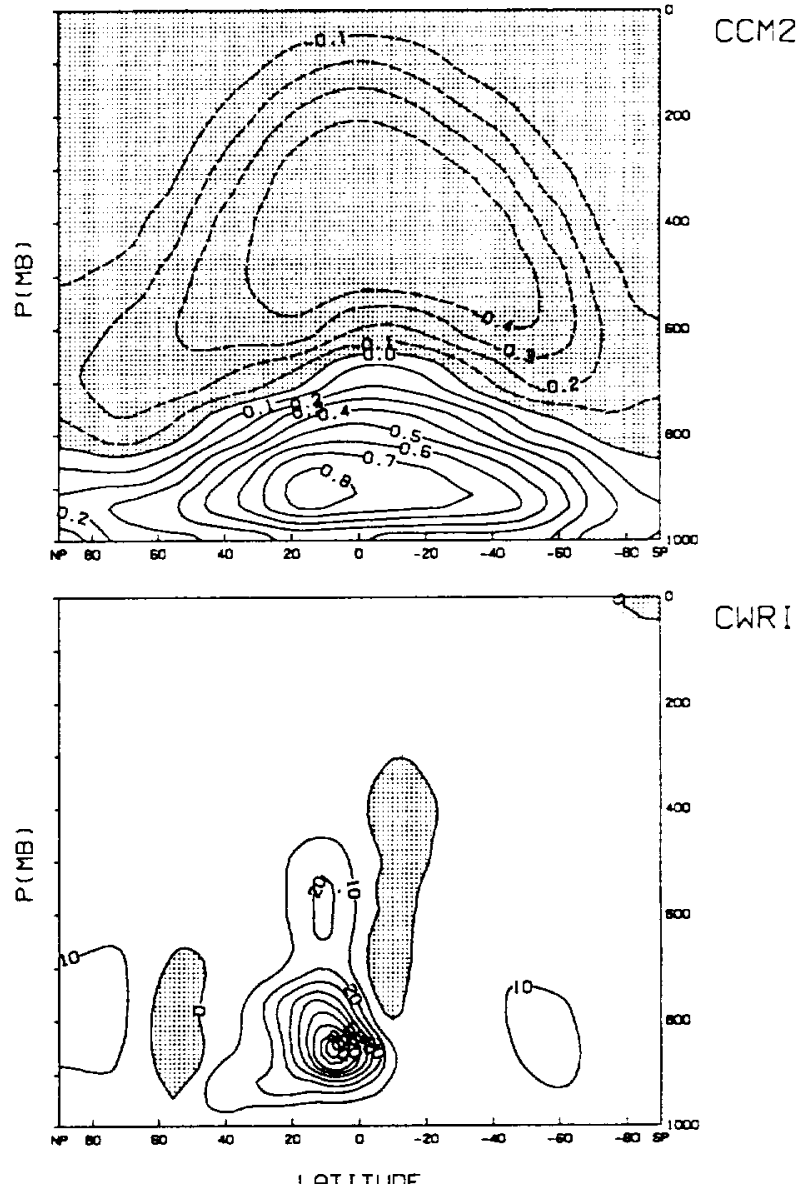

FIG. 13. Height-iatitude cross section of equilibrium changes in cloud water path of CCM2 and CWRI from 60-day perpetual July $\pm 2 \mathrm{~K}$ SST simulations. Contours every $0.1 \mathrm{gm}^{-2}$ and $10 \mathrm{gm}^{-2}$ of CCM2 and CWRI, respectively; regions of reduction are stippled.

CCM2. These include the cumulus convection parameterization of Zhang and McFarlane (1995), the solar radiation parameterization of Fouquart and Bonnel (1980), and the longwave radiation parameterization of Morcrette (1990).

SCM integrations were performed at two different locations. The first group used data collected during TOGA COARE located in the western tropical Pacific. The second group of integrations were located over the U.S. southern Great Plains and used data collected from the ARM program. Both sets of SCM integrations use in situ data to calculate the necessary horizontal advective forcing terms. The main advantage in specifying the forcing terms using in situ data as opposed to threedimensional model analysis products is that the latter may contain biases from the physical parameterizations contained in the three-dimensional model. Each group of SCM integrations consisted of five model runs with the same cloud parameterizations as in the CCM2, CW, CWRF, CWRV, and CWRI schemes described in section 2.

Satellite measurements of outgoing longwave radia- 

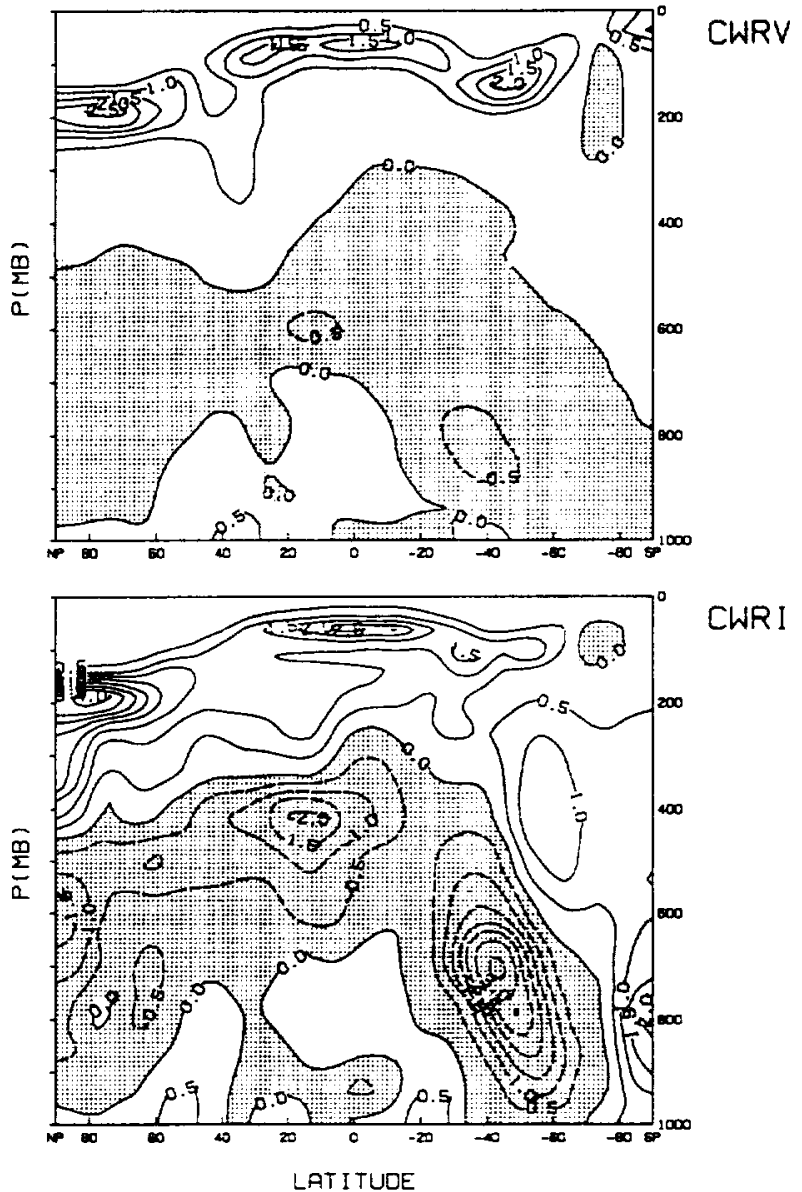

FIG. 14. Height-latitude cross secrion of equilibrium changes in cloud droplet effective radius for CWRV and CWRI from 60-day perpetual July $\pm 2 \mathrm{~K}$ SST simulations. Contours every $0.5 \mu \mathrm{m}$; regions of reduction are stippled.

tion and cloud fraction together with surface measurements of downwelling shortwave radiation are used to validate the model results from each of the five cloud parameterization schemes. By using these three variables for comparison. changes in overall cloud fraction, cloud optical thickness, and cloud-top height are considered. The in situ data used to calculate the forcing terms and the data used to validate the SCM results are discussed below for each location.

\section{b. SCM experiments-Western tropical pacific}

The timing of these SCM integrations coincides with the 4-month Intensive Operations Phase (IOP) of TOGA COARE. The SCM was applied in the atmospheric column directly over the TOGA COARE Intensive Flux Array (IFA). Two land-based sites and two research vessels deployed at stationary sites defined the perimeter of the TOGA COARE IFA, which covers an area of approximately $240000 \mathrm{~km}^{2}$.

Atmospheric soundings consisting of temperature, humidity, and horizontal winds were produced every 6 $h$ at each of these four sites during TOGA COARE throughout the 4-month IOP period of 1 November 1992-28 February 1993. The original radiosonde measurements were quality controlled (for details, see Miller and Riddle 1994) and then interpolated onto evenly spaced vertical levels with constant pressure increments of $5 \mathrm{mb}$. Surface observations of temperature, humidity, wind, precipitation, and radiative fluxes were also obtained at each site and stored as 1 -min averages.

Sounding data from these four sites were used to produce slab averages of temperature, humidity, and horizontal winds for the IFA column. The horizontal divergence at each pressure level was calculated by evaluating the line integral around the IFA perimeter:

$$
\boldsymbol{\nabla} \cdot \mathbf{V}=\frac{1}{A} \oint \mathbf{V} \cdot \mathbf{n} d l,
$$

where $\mathbf{V}$ is the horizontal velocity, $\mathbf{n}$ is the normal vector relative to the IFA perimeter, and $A$ is the area enclosed by the IFA perimeter. Vertical velocities were calculated from the horizontal divergences using the method of O'Brien (1970).

The horizontal advective tendency of temperature was calculated using

$$
\mathbf{V} \cdot \nabla T=\frac{1}{A}[\oint T \mathrm{~V} \cdot \mathbf{n} d l-\bar{T} \oint \mathbf{V} \cdot \mathbf{n} d l],
$$

where $T$ is the temperature and the overbar denotes a spatial average. A similar equation is used for the humidity tendency.

Due to missing and errant data there were several significant gaps in the sounding measurements. As a result, the SCM experiments were limited to three time periods for which near-continuous forcing data was available. These three periods (10 November 1992-11 December 1992, 18 December 1992-22 January 1993, and 31 January 1993-19 February 1993) contain a total of 88 days.

Outgoing longwave radiative flux and fractional cloud amount were obtained from the International Satellite Cloud Climatology Project (ISCCP) Cl flux dataset created in support of TOGA COARE. The dataset is presented with a temporal resolution of $3 \mathrm{~h}$ and a spatial resolution of $2.5^{\circ} \times 2.5^{\circ}$. Downwelling surface shortwave radiative fluxes were obtained from a total of seven surface sites within the IFA. These include the four ISS sites defining the perimeter of the IFA, two ships (R/V Moana Wave and R/V PRC\#5), and the Woods Hole Oceanographic Institution (WHOI) IMET buoy. These seven surface measurements were averaged to produce a single time series of downwelling surface shortwave radiation representative of the entire IFA region. 

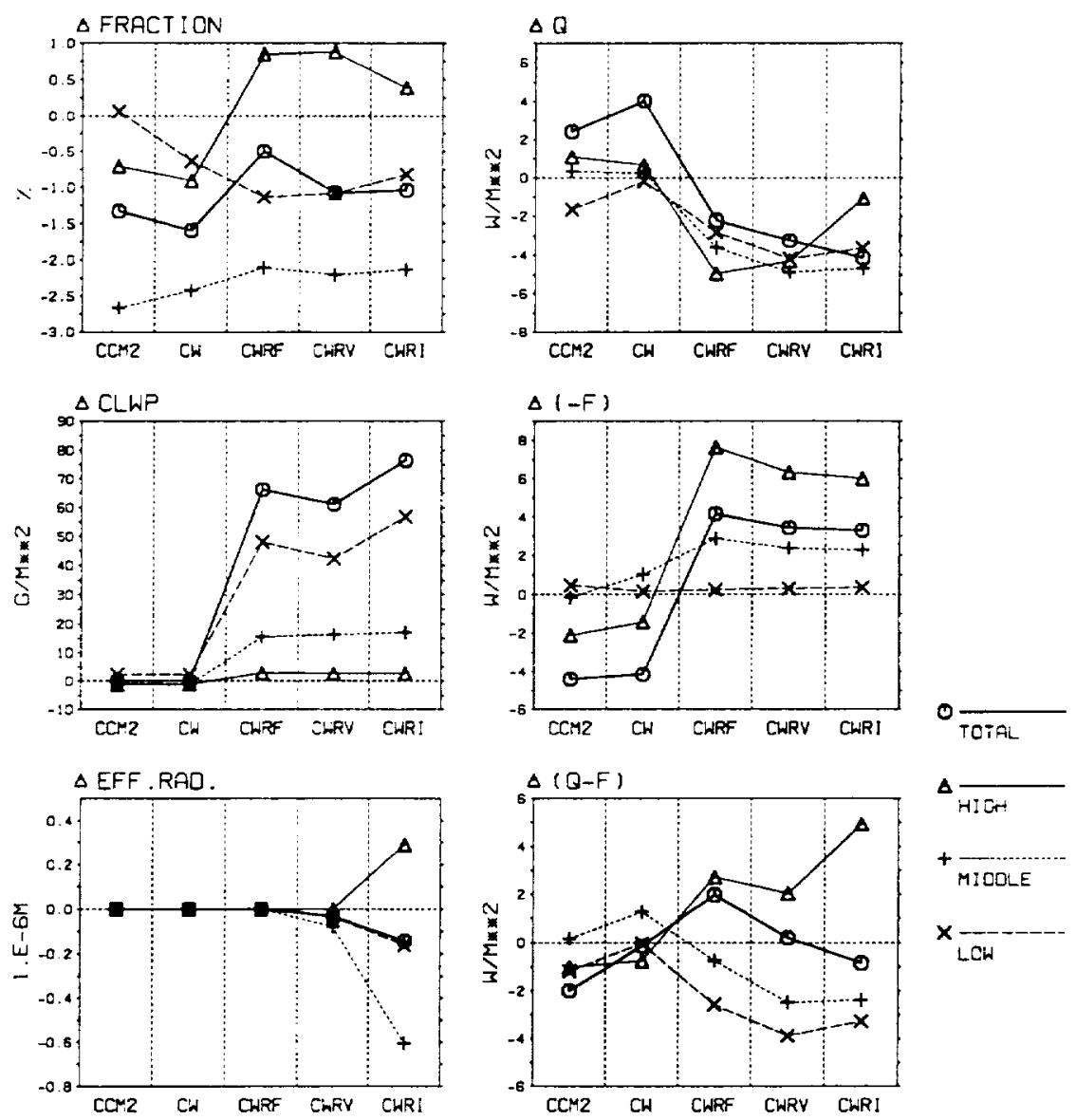

FiG. 15. As in Fig. 9 but for the changes due to $د \mathrm{SST}= \pm 2 \mathrm{~K}$ experiments.

\section{c. SCM experiments-U.S. southern Great Plains}

This set of SCM integrations utilizes data collected at the ARM southern Great Plains (SGP) site during the 21-day fall 1994 IOP (25 October 1994-14 November 1994). During this IOP, radiosondes were launched simultaneously from five different locations every $3 \mathrm{~h}$. These five locations consist of four boundary sites and one central site. The size of the array defined by these boundary sites is approximately $250 \mathrm{~km} \times 250 \mathrm{~km}$. The radiosondes measure the $u$ - and $u$ wind components, temperature, and humidity as a function of pressure. Collocated with the radiosonde launch sites are National Weather Service 404- $\mathrm{MHz}$ radar wind profilers.

Temperature and humidity data from each radiosonde were averaged over $10-\mathrm{mb}$ increments extending from the surface to $100 \mathrm{mb}$ to form "layer" averages. Objective analysis techniques were used to combine the radiosonde wind data and the wind profiler data into layer averages. The wind divergence and horizontal advective tendencies were then calculated by differencing the appropriate layer averages of the four boundary sites. Linear interpolation was used (both spatially and temporally) to fill in any missing data.

Outgoing longwave radiation and fractional cloud amount were derived from GOES-7 measurements (Minnis et al. 1995) and obtained from the NASA/Langley Research Center. A limitation of this dataset is that, due to a lack of cloud optical depth information during nighttime scenes, the nighttime cloud fraction should be regarded with caution. Daytime values of cloud fraction should not be affected. In the data comparisons that follow the total cloud fraction is used in the plots. However, the daytime cloud fractions from both the SCM and the GOES-7 products are noted in the text.

Downwelling shortwave radiation measurements were obtained from a total of 31 surface sites within the ARM SGP site boundary. These included measurements from the ARM central site facility, 2 sites from the Kansas State University Mesonetwork, and 28 sites from the Oklahoma Mesonetwork (Brock et al. 1995). The data from these 31 sites were averaged to produce a single time series of downwelling surface shortwave radiation representative of the ARM SGP site.

\section{d. SCM results}

The model-produced outgoing longwave radiation, downwelling surface shortwave radiation, and cloud 

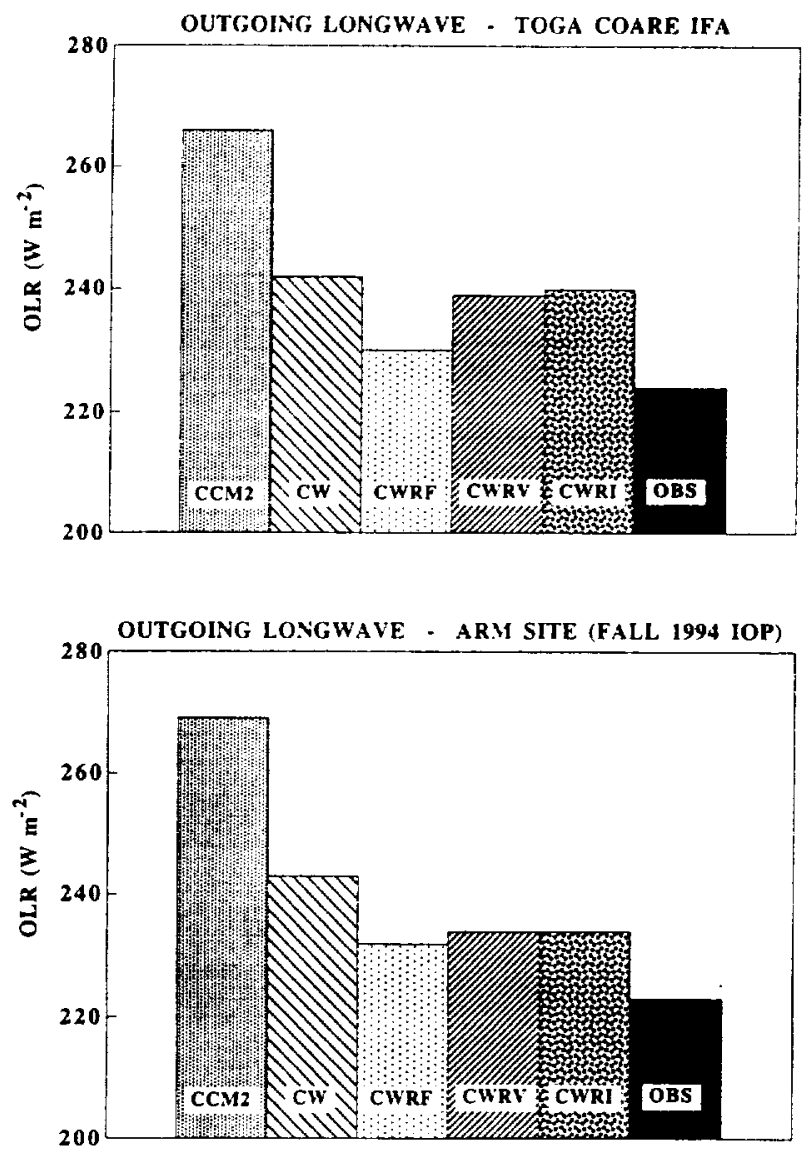

FIG. 16. Comparison between model and observed mean outgoing longwave radiation for each of the five cloud schemes. The results from the SCM experiments over the western tropical Pacific are shown in the top panel while the bottom panel shows the results from the U.S. southern Great Plains.

fraction from each SCM integration (a total of 10 ) were averaged over the length of the model run and then compared to the corresponding observed means. Figure 16 shows the comparison between model and observed outgoing longwave radiation for each of the five cloud schemes. At both the TOGA COARE site and the ARM SGP site the incorporation of prognostic cloud liquid water significantly improves the model outgoing longwave radiation results (CCM 2 vs CW). When the cloud radiative properties are computed as a function of cloud liquid water and/or cloud droplet radius (CWRF, CWRV, or CWRI), further improvement is obtained. However, the improvement is not as great as that between CCM2 and $\mathrm{CW}$.

The modeled and observed mean cloud fractions are shown in Fig. 17. Again, the model results at both sites show a significant improvement with the incorporation of prognostic cloud liquid water. However, very little difference in the modeled mean cloud fraction is seen when cloud radiative properties are computed as a function of cloud liquid water and/or cloud droplet radius (CW vs CWRF, CWRV, or CWRI). The observed cloud
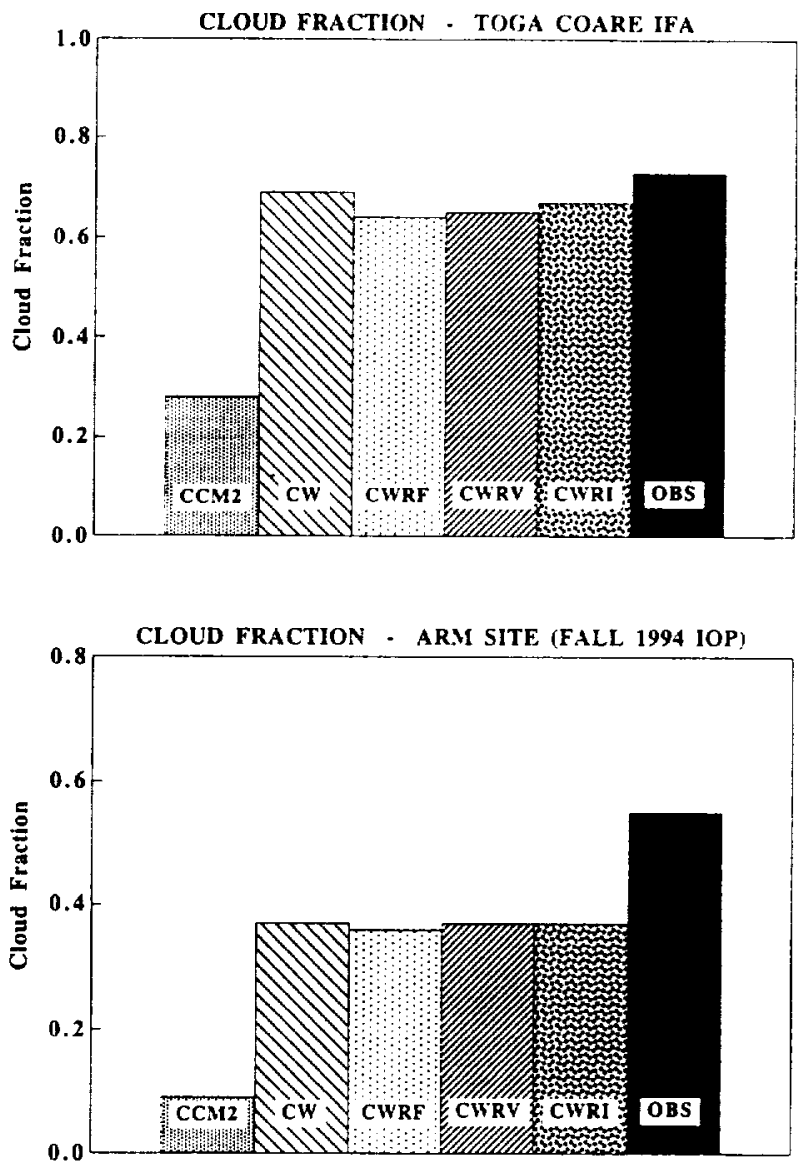

Fig. 17. As in Fig. 16 but for mean cloud fraction.

fraction at the ARM SGP site shown in Fig. 17 is 0.55 and was calculated using both day and nighttime values. If only daytime values are considered, the observed cloud fraction increases to 0.61 . The modeled daytime mean cloud fraction varied less than $5 \%$ from the values shown in Fig. 17. Thus, the limitations of the GOES-7 cloud products discussed above do not appear to alter the results of these comparisons.

Figure 18 shows the modeled and observed mean downwelling surface shortwave radiation. As with the outgoing longwave radiation and the cloud fraction, a notable improvement in the modeled downwelling surface shortwave radiation occurs with the inclusion of prognostic cloud liquid water. When cloud radiative properties are determined from cloud liquid water and/or cloud droplet radius, an additional, albeit smaller. improvement is obtained.

Thus, the inclusion of prognostic cloud water does seem to produce a notable improvement in the realism of the parameterizations, as measured by SCM diagnosis of observations from TOGA COARE and ARM. Of course, the observations themselves have their own shortcomings, as we have noted. Nevertheless, it seems fair to conclude that empirical validation of the tested algorithms demonstrates the value of including cloud 

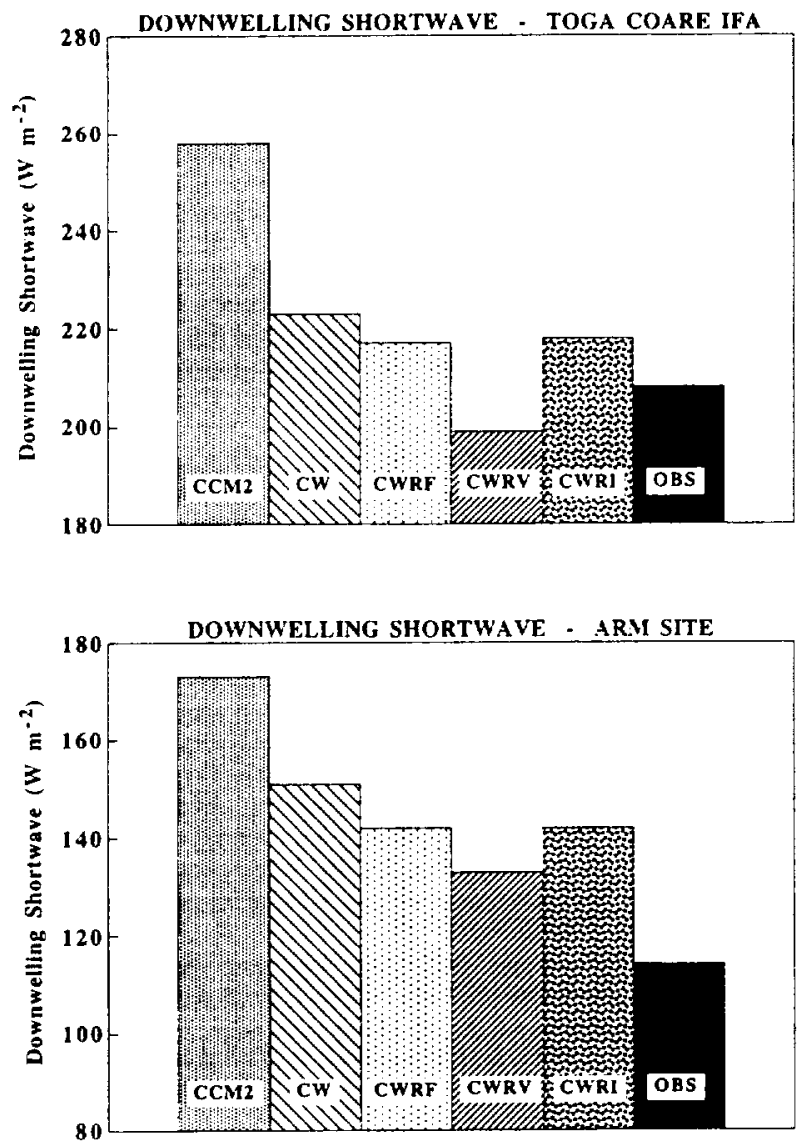

FIG. 18. As in Fig. 16 but for mean downwelling surface shortwave radiation.

water as a prognostic variable. Furthermore, the observational evidence suggests that deriving cloud radiative properties from cloud water content and microphysical characteristics is a promising route to further improvement.

\section{Conclusions}

The cloud cover and radiation fields for simulations of the present climate are strongly sensitive to the cloud radiation scheme adopted. Comparison with satellite observations shows that improvements in all the algorithms are still needed. In the warming experiments, we find either a negative or a positive net cloud feedback depending on which schemes we chose. However, for all the cases with interactive cloud radiative schemes, we find a negative shortwave feedback (i.e.. cloud moderates the warming through its effect on shortwave radiation) and a positive longwave feedback (i.e., cloud amplifies the warming through its effect on longwave radiation), while the opposite is true for the schemes with specified cloud radiative properties. The increase in cloud water content in the warmer climate leads to optically thicker middle and low clouds and in turn to negative shortwave feedbacks for the interactive cloud radiative schemes, while the decrease in cloud amount simply produces a positive shortwave feedback for the other schemes. For the longwave feedbacks, the decrease in high effective cloudiness for the schemes without interactive radiative properties leads to a negative feedback, while the opposite is true for the schemes with interactive cloud radiative properties.

Our results reinforce a major conclusion of Senior and Mitchell (1993), who showed that variations in the cloud radiation algorithm of their GCM could account for much of the typical factor-of-three difference between GCMs (in global sensitivity of surface temperature to greenhouse gas increases) that has been revealed by extensive model intercomparisons. Like they and others, we find significant differences in the magnitudes and even the signs of cloud radiation feedbacks, depending on our choice of parameterizations. It is somewhat unsettling that the results of a modern atmospheric GCM, which may contain several tens of thousands of lines of code, can be affected so much by making what seem to be reasonable changes in only a few of those lines. This sensitivity highlights the need for a thorough understanding of the fundamental physics of clouds and their effects on radiation.

Unfortunately, it is not known which cloud radiation parameterizations are most realistic, or even if any current scheme captures the essential feedback processes of actual clouds. Furthermore, other GCM groups have obtained different results by trying other ways of incorporating cloud microphysical processes and their radiative interaction. There is thus a clear need to intercompare these approaches with one another, and, even more importantly, to validate them against observations. so as to evaluate the strengths and weaknesses of each. For too long, we have had too many theoretically plausible parameterizations and too little research on testing them empirically. By using the single-column model in conjunction with observations from ARM and TOGA COARE, we have carried out a partial validation of several cloud radiation algorithms. The inclusion of prognostic cloud water produces a notable improvement in the realism of the parameterizations. as measured by observations. We conclude that empirical validation of the tested algorithms demonstrates the value of including cloud water as a prognostic variable. Furthermore. the observational evidence suggests that deriving cloud radiative properties from cloud water content and microphysical characteristics is a promising route to further improvement.

Acknowledgments. This research was supported in part by the National Aeronautics and Space Administration under Grant NAG5-2238, the Department of Energy under Grant DE-FG03-90-ER61061, the National Oceanic and Atmospheric Administration under Grant NA36GP0372, the National Science Foundation under Grant ATM91-14109, the University of California and Digital Equipment Corporation under Grant 1243. and 
by a consortium of government and industrial partners, and the University of California Institutional Collaboration Research Program. We thank Yong-Xiang Hu for helpful discussions, Nicola Farnon of the United Kingdom Meteorological Office for providing the updated source code of the cloud water scheme of Smith (1990), and Pat Kennedy for CCM2 documentation and encouragement. The SCM forcing and validation data at the U.S. southern Great Plains site were collected by the Atmospheric Radiation Measurement (ARM) Program sponsored by the U.S. Department of Energy, Office of Energy Research, Office of Health and Environmental Research, Environmental Sciences Division. A portion of these data were obtained from the Colorado State University SCM Web site. The SCM data from the western tropical Pacific were collected during TOGA COARE and were obtained over the Internet from the TOGA COARE International Project Office. We also thank Dr. Robert Weller at the Woods Hole Oceanographic Institution for making the IMET buoy surface flux data available. All of the CCM2 integrations were carried out on DEC Alpha workstations supplied by Digital Equipment Corporation under Project Sequoia 2000. Dana Lane and an anonymous reviewer provided detailed criticism and greatly helped to improve the manuscript.

\section{REFERENCES}

Barkstrom, B. R., 1984: The Earth Radiation Budget Experiment (ERBE). Bull. Amer. Meteor. Soc., 65, 1170-1185.

Bower, K. N., T. W. Choularton, J. Latham, J. Nelson, M. B. Baker, and J. Jenson, 1994: A parameterization of warm clouds for use in atmospheric general circulation models. J. Amos. Sci. 51 , 2722-2732.

Brock, F. V., K. Crawford, R. Elliott, G. Cuperus, S. Stadler, H. Johnson, and M. Eilts, 1995: The Oklahoma Mesonet: A technical overview. J. Atmos. Oceanic Technol., 12, 5-19.

Cess, R. D.. and G. L. Potter. 1988: A methodology for understanding and intercomparing atmospheric climate feedback processes in general circulation models. J. Geophys. Res., 93, 8305-8314.

- - and Coauthors, 1990: Intercomparison and interpretation of climate feedback processes in 19 atmospheric general circulation models. J. Geophys. Res., 95, 16601-16615.

- , and Coauthors, 1996: Cloud feedback in atmospheric general circulation models: An update. J. Geophys. Res., 101, 12791 12794.

Del Genio, A. D., M.-S. Yao, W. Kovari. and K. K.-W. Lo, 1996: A prognostic cloud water parameterization for global climate models. J. Climate, 9, 270-304.

Fouquart, Y., and B. Bónnel. 1980: Computation of solar heating of the Earth's atmosphere: A new parameterization. Beitr. Phys. Almos., 53, 35-62.

Hack, J. J., 1994: Parameterization of moist convection in the $\mathrm{N}_{2}$ tional Center for Atmospheric Research community climate model (CCM2). J. Geophys. Res.. 99, 5551-5568.

—, B. A. Boville, B. P. Briegleb, J. T. Kiehl. P. J. Rasch, and D.
L. Williamson, 1993: Description of the NCAR Community Climate Model (CCM2). NCAR Tech. Note NCAR/TN-382+STR, 108 pp. [Available from National Center for Atmospheric Research, P.O. Box 3000, Boulder. CO 80307.]

Heymsfield. A. J., and C. M. R. Platt. 1984: A parameterization of the particle size spectrum of ice clouds in terms of the ambient temperature and the ice water content. J. Atmos. Sci., 41, 846855.

Miller, E. R., and A. C. Riddle, 1994: TOGA COARE Integrated Sounding System data report-Volume IA revised edition. TOGA COARE International Project Office, $99 \mathrm{pp}$. [Available from TOGA COARE International Project Office, Lniversity Corporation for Atmospheric Research, 1850 Table Mesa Dr., Boulder, CO 80303.]

Minnis, P., W. L. Smith Jr., D. P. Garber, J. K. Ayers, and D. R. Doelling, 1995: Cloud properties derived from GOES-7 for spring 1994 ARM intensive observing period using Version 1.0.0 of ARM Satellite Data Analysis Program. NASA RP-1366, 59 pp. [Available from Patrick Minnis. NASA/Langley Research Center, MS 420, Hampton, VA 23665.]

Mitchell, J. F. B., and W. J. Ingram, 1992: Carbon dioxide and climate: Mechanisms of changes in cloud. J. Climate, 5, 5-21.

Morcrette, J.-J., 1990: Impact of changes to the radiation transfer parameterizations plus cloud optical properties in the ECMWF model. Mon. Wea. Rev., 118, 847-873.

O'Brien, J. J., 1970: Alternative solutions to the classical vertical velocity problem. J. Appl. Meteor., 9, 197-203.

Ramanathan, V., 1987: The role of earth radiation budget studies in climate and general circulation research. J. Geophys. Res., 92, 4075-4095.

- B. R. Barkstrom, and E. F. Harrison, 1989: Climate and the Earth's radiation budget. Phys. Today, May, 22-32.

Randall, D. A., K.-M. Xu, R. C. J. Somerville, and S. lacobellis, 1996: Single-column models and cloud ensemble models as links between observations and climate models. J. Climate. 9, 16831697.

Senior. C. A., and J. F. B. Mitchell, 1993: Carbon dioxide and climate: The impact of cloud parameterization. J. Climate, 6, 393-418.

Slingo, A., 1989: A GCM parameterization for the shortwave radiative properties of water clouds. J. Atmos. Sci., 46, 1+19-1427.

Slingo, J. M., 1987: The development and verification of a cloud prediction scheme for the ECMWF model. Quart. J. Roy. Meteor. Soc., 113, 899-927.

Smith, R. N. B., 1990: A scheme for predicting layer cloud and their water content in a general circulation model. Quart. J. Roy. Meteor. Soc., 116, 435-460.

Somerville, R. C. J., and L. A. Remer, 1984: Cloud optical thickness feedbacks in the $\mathrm{CO}_{2}$ climate problem. J. Geophys. Res., 89, 9668-9672.

Spencer, R. W., 1993: Global oceanic precipitation from the MSU during 1979-92 and comparisons to other climatologies. J. Climate, 6, 1301-1326.

Sundqvist, H., 1981: Prediction of stratiform clouds: results from a 5-day forecast with a global model. Tellus. 33, 242-253.

Suzuki, T., M. Takana, and T. Nakajima, 1993: The microphysical feedback of cirrus cloud in climate change. J. Meteor. Soc. Japan, 71, 701-713.

Zhang, G. J., and N. A. McFarlane. 1995: Sensitivity of climate simulations to the parameterization of cumulus convection in the Canadian Climate Centre general circulation model. Atmos.Ocean, 33, 407-446.

Zhang, M. H., J. J. Hack. J. T. Kiehl. and R. D. Cess, 1994: Diagnostic study of climate feedback processes in atmospheric general circulation models. J. Geophys. Res. 99, 5525-5537. 